Review

\title{
Polymers and Polymer Nanocomposites for Cancer Therapy ${ }^{\dagger}$
}

\section{Dorel Feldman}

Faculty of Engineering and Computer Science, Concordia University, 1455 De Maisonneuve Bvld. West, Montreal, QC EV 6-403, Canada; feldman@bcee.concordia.ca; Tel.: +(514)-848-2424 (ext. 3202)

+ Review dedicated to the memory of Edith and Tony both passed away because of cancer.

Received: 10 August 2019; Accepted: 12 September 2019; Published: 17 September 2019

check for updates

\begin{abstract}
Synthetic polymers, biopolymers, and their nanocomposites are being studied, and some of them are already used in different medical areas. Among the synthetic ones that can be mentioned are polyolefins, fluorinated polymers, polyesters, silicones, and others. Biopolymers such as polysaccharides (chitosan, hyaluronic acid, starch, cellulose, alginates) and proteins (silk, fibroin) have also become widely used and investigated for applications in medicine. Besides synthetic polymers and biopolymers, their nanocomposites, which are hybrids formed by a macromolecular matrix and a nanofiller (mineral or organic), have attracted great attention in the last decades in medicine and in other fields due to their outstanding properties. This review covers studies done recently using the polymers, biopolymers, nanocomposites, polymer micelles, nanomicelles, polymer hydrogels, nanogels, polymersomes, and liposomes used in medicine as drugs or drug carriers for cancer therapy and underlines their responses to internal and external stimuli able to make them more active and efficient. They are able to replace conventional cancer drug carriers, with better results.
\end{abstract}

Keywords: polymers; biopolymers; nanocomposites; micelles; hydrogels; polymersomes; liposomes; drug carriers; cancer therapy

\section{Introduction}

Cancer has been the most deleterious disease in recent times, and unfortunately its spread is increasing. Taking into account this grave health situation, scientists are trying to develop novel carriers for anticancer drug delivery specifically aimed at cancer tumors [1].

Millions of people are diagnosed with cancer globally each year, and more than a half of them die. Every year, the American Cancer Society estimates the numbers of new cancer cases and deaths that will occur in the USA and compiles the most recent data on cancer incidence, survival, and mortality. In 2019, 1762.450 new cancer cases and 606.880 cancer deaths are projected to occur in the USA. From 2006 to 2015, the cancer incidence rate was stable in women and declined by approximately $2 \%$ per year in men, whereas the cancer death rate from 2007 to 2016 declined annually by $1.4 \%$ and $1.8 \%$, respectively. A broader application of existing cancer control knowledge with an emphasis on disadvantaged groups could possibly accelerate progress toward finding a cure for cancer [2].

Following cardiovascular diseases, cancer is the second-most prevalent cause of death in the world. Globally, about $20 \%$ of cancer patients suffer from breast cancer. It is a group of diseases that involve the uncontrolled proliferation of cancer cells. The most used treatments against cancer are radiotherapy, chemotherapy, immunotherapy, hormonal therapy, and surgery. Chemotherapy, a cancer treatment based on using drugs (chemicals), is one of the most important techniques in treating tumors, along with surgery and radiation. The drug resistance of cancer cells is one of the major challenges in chemotherapy. Simultaneous delivery of two or more therapeutic agents has received much attention recently because it may produce better anticancer results [3]. Polymer 
nanocomposites offer numerous opportunities in diverse applications, including nanocarriers, tissue engineering, antimicrobials, sensors, etc. These new groups of materials have gained significant research interest due to their novel properties, which are gained through the addition of nanofillers. Polymer nanocomposites have significant potential in disease theranostics, and nanotechnology brings great promise in cancer drug carriers [4].

Chemotherapy implies the use of drugs and, besides the drugs, carriers. Common products used as carriers include synthetic polymers, biopolymers, and polymer nanocomposites.

Some of the most useful drugs for chemotherapy are toxic chemicals able to inhibit the proliferation of cancer cells. The use of chemotherapeutic drugs has been in part hindered by their poor solubility in water, their short biological half-life, their lack of targeting ability, and the development of multidrug resistance [5]. In the last decades, nanoparticles have shown significant promise as an oncology treatment modality. Responsive polymers represent a promising class of nanoparticles that can trigger delivery through the exploitation of a specific stimuli. Response to a stimulus is one of the most basic processes found in living systems. A tutorial review highlighted the recent developments in polymer-based approaches to internally responsive nanoparticles for oncology [6].

One important goal of medicine is to develop carriers that can selectively deliver anticancer drugs to tumor cells with no or minimal side effects in healthy cells $[7,8]$.

Polymers and their nanocomposites in different forms, such as micelles, hydrogels, polymersomes, and liposomes, have important potential in cancer diagnosis and treatment.

Nanocomposites are popular in many areas due to properties such as their unique design capacity, eco-friendly nature, easy production, and cost-effectiveness. In composites, interactions between the polymer matrix and the nanofiller are critical in determining the properties of the hybrid structure [9].

Polymers that respond to various stimuli offer a drug delivery platform at a controlled rate and in a stable and biologically active form [10].

Among the many cancer-fighting chemicals that are often used is DOX (Doxorubicyn or Adryamicine), which is 4-substituted-2,5-dimetoxyamphetamine: it is a commonly used drug widely applied in combination with other chemotherapeutic agents for the treatment of some leukemias and lymphomas, multiple myeloma, and cancer of the bladder, stomach, breast, ovaries, lung, and thyroid. However, small doses of DOX administered over a period of several months raise the incidence of life-threatening side effects such as cardiomyopathy, with myelosuppression and acute bowel infection [11].

\section{Synthetic Polymers and Polymer Nanocomposites}

Polyesters from camphoric acid and group IV B metallocene dichlorides are very effective in inhibiting cancer cell lines, including two pancreatic cell lines. They could represent a new group of anticancer drugs [12].

A dual-responsive amphiphilic random copolymer based on tri (ethylene glycol)-methyl ether methacrylate and [1'-(2-acryloxy)-3,3'-dimethyl-6-nitrospiro-(2H-1-benzopyran-2,2'-indoline)] carrying DOX has proven its effectiveness in the case of cancer therapy [13].

Two novel multistimuli-responsive drugs for theranostic application polymers, an ( $\mathrm{N}$-isopropyl acrylamide-co-itaconic anhydride) copolymer and a macrobranched terpolymer resulting from its partial esterification with monometoxy poly (ethylene glycol) (PEG), have been obtained. Their hybrids with $\mathrm{Fe}_{3} \mathrm{O}_{4}$ nanoparticles have produced nanocomposite carriers [14].

Nanotechnology has lately gained increased attention for its effective diagnosis and treatment of some cancer tumors. Nanocarriers have been used to replace conventional antitumor drug delivery platforms due to their nonspecificity, the lack of side effects, their burst release, and the lack of damage to normal cells. Nanocarriers improve the therapeutic efficiency of antitumor drugs and are able to provide preferential accumulation at the targeted site. Only a limited number of nanocarriers are clinically approved for their intended actions at targeted sites [15]. 
As a novel drug delivery system, nanocarriers have an important role in cancer therapy. In contrast to conventional chemotherapeutic drugs with many restrictions, stimuli-responsive delivery systems can carry antitumor drugs that target the specific sites of a tumor. Due to a precise stimuli response effect, drug delivery systems can control the release, reduce the damage to normal tissue and organs, and decrease side effects [16].

Polyester/ether urethanes (PURs) can be an interesting alternative for the preparation of nanocarriers in the place of traditionally used biodegradable polyesters. PURs can be easily designed to modulate a hydrophilic/hydrophobic balance and to embed specific functionalities, thus representing a promising solution as a targeted delivery system [17].

Poly (cyclotriphosphazene-co-dopamine) microspheres as controlled drug carriers were investigated using acriflavine as a model drug. The microspheres had a $19.5-\mathrm{mgg}^{-1}$ drug storage capacity and sustained release properties of up to 7 days, with $29 \%(\mathrm{pH} 5.0)$ and $47 \%$ (pH 7.4) at $37^{\circ} \mathrm{C}[18]$.

Nanopolymers such as poly(lactic acid) (PLA), PEG, poly(vinyl pirrolidone-co-vinyl acetate) copolymer, poly(acrylic acid) (PAA), and poly(vinyl alcohol) (PVA)-co-albumin copolymer for the nanodelivery of the Sorafenib drug have been reported [19].

Polyurethane (PU)-DOX nanoparticles were prepared in water through electrostatic interactions between amphiphilic $\mathrm{PU}$ and carboxyl pending groups (PU-COOH and $\mathrm{DOX} \mathrm{HCl}$ ). The tests performed demonstrated that PU-DOX nanoparticles had a higher level of cellular internalization and a higher inhibition effect on the proliferation of breast cancer (MCF-7) cells than did pure DOX [20].

Heparin-biotin/heparin/ $\mathrm{CaCO}_{3} / \mathrm{Ca}$ phosphate/deoxyribonucleic acid (DNA)/DOX nanoparticles exhibited $\mathrm{pH}$ sensitivity and tumor-targeting characteristics due to the presence of inorganic components and biotin in the macromolecular chain [21].

Spherical nanopolymers (200 nm) based on poly (1-lactide-co-glycolic acid) (PLGA), which has been used for biomedical applications and on the biopolymer poly(3-hydroxy butyrate) $\mathrm{P}(3 \mathrm{HB})$, were used for the core formation and delivery of Docetaxel (DTXL). No significant difference was observed in terms of the internalization rate and cytotoxicity potential. The research demonstrated that $\mathrm{P}(3 \mathrm{HB})$ could be a valid alternative to the more conventional PLGA for the delivery and controlled release of hydrophobic therapeutic molecules [22].

Dendrimers (nanosized synthetic polymers) with nanogold particle (nAu) hybrids have been demonstrated to be unique nanoplatforms for the production of various multifunctional nanodevices in diverse fields of biomedical applications, including drug delivery, diagnostics, and therapies [23].

A thermoresponsive terpolymer made of diethylene glycol methyl methacrylate, oligoethylene glycol methyl methacrylate, and 2-aminoethyl methacrylate was used as a drug carrier for DOX. Hydrolysable carbamate bonds of the terpolymer allowed for nanoparticle disintegration and the release of the drug at various $\mathrm{pH}$ levels with or without an enzyme [24].

A pH-responsive drug nanocarrier based on magnetic mesoporous silica nanoparticles ( $\mathrm{nSi}$ ) and PEG-co-poly (vinyl pyridine) (PEG-co-PVP) has been used for DOX release. The research found that the obtained carrier was applicable to an in vivo essay due to favorable particle size and high colloidal stability [25].

A novel controlled drug delivery with dual $\mathrm{pH}$ and thermal responses was designed based on the same nSi nanoparticles anchored by ß-cyclodextrin and coated by poly( $\mathrm{N}$-isopropyl acrylamide). This nanocarrier could have the potential to be used in tumor therapy [26].

The drug Naproxen was entrapped in a copolymer based on methacrylic acid (MMA) and a mesoporous nanostructured silica (MCM-41). The profiles for in vitro release were established separately in both enzyme-free simulated gastric (SGF, pH 1) and simulated colonic (SCF, pH 7.4) fluids. The release rates of the SCF were higher than those of the SGF. The study also showed that the silanol groups of MCM-41 played a role in drug entrapment efficiency [27].

Using amphiphilic polymers based on PEG and bis-pyrene with a disulfide (SS) bond as reduction linker, a novel nanoparticle system has been obtained that was able to upregulate the reactive oxygen 
level under UV irradiation in cancer cells, leading to their apoptosis. Maximum release occurred at $\mathrm{pH} 5.5$, the $\mathrm{pH}$ of endosomes [28].

To study antitumor targeting and therapy effects, polyaminoamide dendrimers were partially neutralized on their surfaces through the covalent bonding of 2,3-dimethylmaleic anhydride, and DOX was encapsulated in these nanoaggregates to study their antitumor targeting and therapy effects. It was found that these nanoaggregates could realize effective deformation without external additional stimuli for cancer therapy [29].

A nanofiber made of poly(vinyl pirrolidone) as a shell and hyperbranched poly(ethylene adipate) as a core that contained the Artenisimin (ART) drug was produced. An [3-(4,5 dimethyl-2 thiazolyl) (2,5 diphenyl-2H-tetrazolium bromide)] MTT assay showed that this polymer nanocomposite contributed to reducing prostatic cancer cell viability [30].

A polymer nanocomposite made of polyethyleneimine with a zwitterionic function and paramagnetic iron nanoparticles $\left(\mathrm{nFe}_{3} \mathrm{O}_{4}\right)$ was researched as a carrier for DOX delivery. Studies on magnetic targeting and the evaluation of pharmacokinetic and biodistribution data should be initiated to confirm the efficiency of $\mathrm{Fe}_{3} \mathrm{O}_{4} @$ folic acid (FA)-poly(ethylene imine succinate conjugated)-DOX-loaded nanoparticles as a valuable drug carrier [31].

From a biomimetic point of view, it can be difficult to design, synthesize, and apply polymer therapeutics, but they can offer the advantages of low toxicity, targeting, and selectivity through the incorporation of compounds such as cell signaling and core-shell morphology, which guarantees circulation and accumulation at the site of action. Theranostic characteristics have also been of great importance in new developments [32].

Recent advancements in medicine technologies have provided evidence that besides polymer drug carriers, their nanocomposites have the possibility of replacing conventional drug carriers due to their nonspecificity, lack of side effects, lack of damage to healthy cells, and sensitivity to internal and external stimuli.

\section{Biopolymers and Biopolymer Nanocomposites}

By definition, a biopolymer is any polymer that can be degraded by enzymes or through decomposition from the actions of bacteria or fungi. Biopolymers are commonly used in biomedical and healthcare applications. Their nanocomposites are gaining attention for use as antimicrobials, drug carriers, and sensors and in disease diagnosis, tissue engineering, wound healing, and cancer therapy. Biopolymer nanocomposites are very good at holding, protecting, and releasing bioactive drugs such as pharmaceutics, nutraceuticals, enzymes, and probiotics. A review emphasized the source of biopolymers and their various uses, including cancer drug carriers [33].

Biopolymers can be classified as the following:

(a) agro-polymers based on the biomass of agro-resources as raw materials (e.g., starch and cellulose);

(b) polymers based on microbial production (e.g., polyhydroxyalkanoates),

(c) polymers that are synthesized by using biomass-based monomers (e.g., PLA) [34].

They are especially desired due to their biocompatibility and biodegradability. For special purposes, insoluble biopolymers such as collagen, elastin, chitosan (CS), keratin, and silk can be converted into soluble derivatives through chemical and enzymatic hydrolysis. CS as a drug carrier and curcumin (CUR) as a cancer drug are widely (and mainly) used for chemotherapy. CS applications in medicine and pharmacy are due to its biocompatibility, high charge density, nontoxicity, and mucoadhesion [35].

Polysaccharides have been recognized and applied as promising candidates in biomedical and biotechnological applications, such as diagnosis, bioactive therapy, controlled drug delivery, gene therapy, theranostics, cell encapsulation, tissue engineering, and medical devices, as a benefit of their biocompatibility, biodegradability, inherently low immunogenicity, and unique bioactive properties [36]. 
CS is a unique cationic polysaccharide derived from chitin, which is extracted from the shells of crabs and other crustaceans. The main advantage of using this polysaccharide for biomedical applications is that its properties can be tailored according to the end use application. CS also has colloidal stability, a tunable membrane, and the ability to encapsulate or integrate a broad range of drugs. CS-based matrices have been effectively used for the controlled delivery of many biomolecules, ranging from small drug molecules to biopolymers [37].

DOX $\mathrm{HCl}$ was loaded onto a nanocarrier made of CS-poly(methacrylic acid) shell and $\mathrm{nFe}_{3} \mathrm{O}_{4}$ through electrostatic interactions and strong $\mathrm{H}$ bonds. The results obtained suggest that this nanocarrier can provide a promising anticancer drug delivery system to effectively reduce the side effects of the drug in healthy tissues [38].

To improve the residence time of the chemotherapeutic agent, the sustained-release properties of a biodegradable nanocarrier drug system were used. The advantages were the characteristics of the 5-fluorouracil (5-FU)-loaded CS nanoparticles. The sustained release of 5-FU-CS could solve the short half-life problem of 5-FU in hospital use and reduce the side effects caused by frequent drug administration [39].

The combination of CS and graphene can lead to a promising carrier for the loading and controlled release of therapeutic agents [40].

Silver nanoparticles (nAgs) have attracted a great deal of attention in biomedical research, especially in cancer theranostics. Biocompatible polymers such as PEG, pol(vinyl pyrolidone) (PVP), and CS were used for the reduction of $\mathrm{Ag}$ salt. In addition to the cancer activity and toxicity of biopolymer nAgs being assessed through synthesis in different conditions and with different properties, they were assessed against breast adenocarcinoma, human lung adenocarcinoma, and mouse embryonic fibroblast cell lines. An effective suppression of the proliferation of cancer cell growth was found [41].

$\mathrm{Ag}$ chloride/polypyrrole (PP)/CS, an AgCl/PP/CS core-shell nanocomposite, was prepared by in situ oxidative polymerization of pyrrole using ferric chloride in the presence of CS and Ag nitrate to develop a carrier and controlled release system for 3-amino-2-phenyl-4(3H)-quinazoline (I). For a comparison, $\mathrm{PP} / \mathrm{CS}$ core-shell nanoparticles were prepared and loaded by I. The study revealed that loaded $\mathrm{AgCl} / \mathrm{PP} / \mathrm{CS}$ exhibited excellent antibacterial and anticancer efficacy against Ehrlich ascite carcinoma cells [42].

Poly(d,l,-lactic-co-glycolic acid) (PLGA) is the most frequently used biodegradable and biocompatible polymer in terms of preparation nanoparticles for biomedical applications. It was prepared to obtain nanocarriers for the Pt-based antitumor drug Carboplatin. In order to improve its delivery, folic acid (FA)-conjugated CS (FA/CS/PLGA) nanoparticles have been produced. The modified PLGA nanoparticles are expected to enhance cellular uptake for tumor accumulation promoted by embraced permeability and a retention effect [43].

Release studies have indicated that CS beads coated with $\mathrm{pH}$-dependent poly(acrylic acid) PAA-PVP polyblends offer much protection from drug release in simulated gastric fluid. A controlled release of the drug Dexamethasone from CS was observed once the coating layer of the $\mathrm{pH}$-dependent polymer complex started to dissolve at a higher $\mathrm{pH}$ (6.8). It was concluded that the CS nanoparticles coated with PAA-PVP complexes can be used for effective controlled delivery of the drug directly to the colon [44].

A composite made of CS, hydroxy apatite (HAP), and a glycopolymer grafted on a Cloisite 30B clay surface (CS/HAP/clay-g) and another one based on CS/HAP pristine Cloisite 30B (CS/HAP/clay-g) have been synthesized. Their cytotoxicity was tested against breast carcinoma cell line (Hep G-2) and a normal human skin fibroblast cell line (BJ-I) using an MTT as well as a lactate dehydrogenase assay. The results showed that the biopolymer composite CS/HAP/clay-g can be used in biomedical applications [45].

Besides other already discussed properties, CS nanocomposites have the ability to increase retention time and thus are able to release drugs for a longer time, making them an ideal drug delivery vehicle. Study of the drug delivery behavior of nanostructured CS composites may lead 
to the realization of more effective vehicles in drug delivery systems. The therapeutic application of nanostructured CS composites in various types of cancers, such as bladder cancer, breast cancer, pancreatic cancer, metastatic cancer, lung cancer, colon cancer, and prostate cancer, is being focused on [46].

FA-modified carboxy methyl CS was polymerized with N-3-acrylamidophenyl boronic acid monomer to prepare tumor-targeting nanoparticles that enhanced drug accumulation in tumors, which finally increased antitumor efficiency in $\mathrm{H} 22$ tumor-bearing mice [47].

The anticancer effect of Alphastatin (AS), a 24-amino acid peptide, is limited by its short half-life and degradation in the body. The prepared AS/CS nanoparticles had a sustained release of 6 days and were stable in serum for at least $24 \mathrm{~h}$. In a subcutaneous LA975 lung carcinoma xenograf T739 mouse model, the nanoparticles significantly inhibited tumor growth, tumor volume, and microvessel density, and the antitumor effect was even stronger than that of AS. The study indicated that AS/CS nanoparticles inhibited the SphK1 signaling pathway and enhanced the antiangiogenic effect of the drug both in vitro and in vivo [48].

In one study, the researchers grew colon and hepatocellular carcinoma cells (HCCs) on CS membranes and evaluated the tumor progression and cancer stem cell (CSC) properties. The results showed that developing cancer cells on CS increased cell motility, drug resistance, quiescent population, self-renewal capacity, and the expression levels of stemness and CSC marker genes. The CS culture system provides a convenient platform for research on CSC biology and the screening of anticancer drugs [49].

Ketoprofen-loaded CS was made by modifying cytoprotective nonionic block copolymer poloxamer 188 (a non-ionic linear copolymer composed of two hydrophilic side chains and a hydrophobic center core) and also varying the time and amplitude of ultrasonication [50].

Nanoparticles were also prepared by ionic gelation between CS and tripolyphosphate. Following their study, the researchers considered that one may anticipate their contribution to the advancement of a gene and drug delivery system [51].

Micro/nanoparticles of CS-grafted PEG methacrylate (PEGMA) (CS-g-PEGMA) with a size ranging from 200 to $900 \mathrm{~nm}$ were prepared through double-crosslinking (ionic and covalent) applied in a reverse emulsion technique. The carrier obtained showed nontoxicity and hemocompatibility, and it is considered to be a potential delivery agent for the controlled release of Bevacizumab, an ophthalmic drug. The other benefits of this carrier are a lower administered dose, prolonged release, the effectiveness of local delivery, and targeted administration through local injection next to the retina [52].

The roles and mechanisms of Cyclocarya paliurus polysaccharide (CPP) have been investigated. The results of the study suggested that CPP may enhance thyroid cancer cell apoptosis by suppressing the activation of $\mathrm{p}-\mathrm{Akt}, \mathrm{Akt}$, and $\mathrm{Bcl}-2$ and activating Bax, which provides for the novel use of $\mathrm{CPP}$ as a thyroid cancer treatment [53].

CUR is the principal curcuminoid of turmeric, a member of the ginger family, which is often used as a drug against cancer tumors. Its application as a viable drug is impeded by its low solubility. For efficient delivery at the cancer tumor site, amphiphilic block copolymers made of poly (alckyl-2-oxazoline) (PAOx) were synthesized. The CUR-loaded PAOx nanoparticles, sized around $100 \mathrm{~nm}$, exhibited excellent stability and enhancement of the aqueous solubility of CUR. In vitro release studies demonstrated their potential chemical relevance as a promising nanocarrier able to circumvent the limitations of CUR [54].

Thiolated starch-coated nano-iron oxide particles $\left(\mathrm{nFe}_{3} \mathrm{O}_{4}\right)$ containing CUR was developed to investigate cytotoxicity in lymphocytes and cancer cell lines. Nanoparticles with a $5 \%$ polymer coating showed a drug encapsulation efficiency up to $78 \%$, while the loading efficiency was greater than $80 \%$. A cytotoxicity assay revealed excellent compatibility of the system with lymphocyte cells, while it still had a considerable amount of cytotoxicity in cancer cell lines [55]. 
A bioconjugated alginate (AA)-CUR, was synthesized and used to prepare stable calcium crosslinked spherical micelles serving as a carrier for CUR. The bioconjugate, at a concentration of $0.7 \mathrm{mg} / \mathrm{mL}$, decreased the viability of cancer cells by about $80 \%$. The cellular uptake of AA-CUR was detected within one hour after treatment. The AA-CUR micelles can serve as an effective and safe delivery vehicle for CUR [56].

To evaluate metoxy-PEG-b-poly ( $\delta$-valerolactone) (mPEG-b-PVL) as a carrier, CUR was loaded in the copolymer using thin film hydration. The encapsulation efficiency and yield CUR released from the nanoparticles continued for one month. The nanoparticles obtained ( $130 \mathrm{~nm}$ in size) could obviously increase CUR solubility in water and improve its pharmacokinetic properties. The results of the research confirmed the potential of the mPEG-b-PVL copolymer as a carrier for CUR [57].

Functional multilayer polymeric micelles were obtained through the self-assembly of a poly(ethylene oxide)-b-poly (n-butyl acrylate)-b-poly (acrylic acid) (PEO-b-PnBA-b-PAA) triblock terpolymer and exploited like a template for $n A g$ being bound by a PAA block. CUR was loaded in the hydrophobic PnBA micellar cores. The effect of a combination of two anticancer agents released from the micelles on the vitality of acute myeloid leukemia (HL-60), its multidrug-resistant subline HL60/DOX, and human urinary bladder carcinoma (Ej) cells was assessed. The in vitro experiments revealed efficacy with regard to the cytotoxic activity of nAg and CUR nanoparticles [58].

(Metoxy-PEG-b-PLA) diblock copolymers were also used as carriers for CUR. These block copolymers were noncovalently loaded with CUR, a CUR bortezomib complex, and a CUR bortezomib model. The results of the research suggested that the mPEG-b-PLA nanoformulations can be useful as carriers of CUR in breast cancer [59].

Dextran/nSi biopolymer nanocomposites were studied as a potential theranostic system for bioimaging and sonodynamic therapy. This type of biopolymer nanocomposite exhibited enhanced stability in water. In vitro experiments revealed the low cytotoxicity of dextran-coated nSi nanoparticles in comparison to uncoated ones, a fact that suggests that the former be used for medical purposes. Therapeutic ultrasound irradiation of cancer cells with the incorporated nSi resulted in a decrease in the number of living cells, while the total number of cells remained nearly constant. The results show the possibilities of applications of porous $\mathrm{nSi}$ with dextran coating in both diagnostics and cancer sonodynamic therapy [60].

Two different fluorescent block copolymers of PLA and PEG containing grafted fluorescein were synthesized. Plaxitel-loaded fluorescent microspheres were prepared from the grafted copolymers, and they proved to have anticancer activity against the colorectal cancer cell line Caco-2 [61].

The efficient delivery of Daunorubicin-loaded PLA with multiwall carbon nanotubes (MWCNTs) and iron oxide (PLA/MWCNT/ $/ \mathrm{Fe}_{3} \mathrm{O}_{4}$ ) composite nanofibrous scaffolds was investigated from the point of view of a proliferation inhibitor effect on leukemia K562 cell lines. The effect of nanofiber concentration on drug delivery in the absence or presence of an external magnetic field was also evaluated. The results indicated that the incorporation of Daunorubicin into prepared nanofiber scaffolds under an applied magnetic field could have synergistic cytotoxic effects on leukemia cancer cells [62].

The clinical applications of DOX have been limited due to its nonselective cytotoxicity, which leads to adverse effects. In recent research, dextran-coated goldmag (GM) nAu/ $\mathrm{Fe}_{3} \mathrm{O}_{4}$ particles (DGMNs) were synthesized and validated as a potential carrier for DOX. Under the guidance of an external magnetic field, the cytotoxicity of the drug and carrier composite was evaluated in hepatocellular carcinoma cell lines and in tumor grafts. The study showed that DGMNs are a promising drug delivery carrier for magnetically targeted cancer therapy [63].

In order to improve the outcome of chemo-photothermal cancer therapy, poly- $\gamma$-glutamic acid-g-poly(lactic-co-glycolic acid) nanoassemblies were developed to serve as carriers of DOX and indocianine green (ICG). Taking advantage of acid-triggered rapid DOX release combined with photoinduced hyperthermia and singlet oxygen generation to facilitate the accumulation of DOX within the nucleus, even at a low dosage, the DOX/ICG-loaded polymer nanoassemblies effectively 
suppressed the proliferation of cancer cells. Based on the findings, the DOX/ICG-loaded assemblies displayed a great potential for augmenting the efficacy of chemo-photothermal cancer therapy [64].

The use of marine biopolymer (algae)/nanofillers for theranostic applications was evaluated in a recent review, addressing potential uses in drug delivery and various therapies such as photothermal, photodynamic, and hyperthermia therapy as well as photoacoustic imaging, magnetic resonance imaging (MRI), and computed tomography. Although many synthetic polymers and biopolymers are used for surface modifications of $\mathrm{Au}, \mathrm{Ag}$, magnetic mesoporous $\mathrm{nSi}$, and other nanoparticles in biomedical applications due to their excellent biocompatibility, biodegradability, nontoxicity, low cost, and abundant renewable sources, the research and development of the theranostic application of marine biopolymer-based nanomaterials is still in its initial exploration phase. The most recent progress in the compatibility of the marine biopolymer nanocomposites in vitro and in vivo was discussed, along with their future treatment of cancer, in Reference [65].

A nano-biodegradable polymer blend made of starch and cellulose acetate-co-acrylate was loaded with DOX. The antiproliferative effect of the drug slowly released from the nano-biodegradable polymer illustrated growth inhibition potency toward the human colon and liver cancer cell lines LoVo and Hepg2 [66].

Research has investigated the controlled delivery of Camptothecin and DOX through encapsulation in self-assembled hyaluronic acid (HA)/testosterone conjugate nanoparticles. Based on the results of in vitro studies, the researchers concluded that the HA/testosterone nanocomposite is a promising carrier candidate in the chemotherapy of cancer [67].

In order to study multidrug resistance, environment-sensitive polylactide-based nanoparticles (100-150 nm) with low toxicities were assembled through multiple hydrogen bonds. Most importantly, the finding of this research was that drug resistance in the case of cancer cells could be overcome through the use of tailor-made nanoparticles, which were biodegradable and $\mathrm{pH}$-responsive. These features indicated that supramolecular nanocarriers can effectively increase the efficiency of chemotherapy against the drug resistance of cancer tumors [68].

Polylysine-coated Tamoxifen-loaded poly(lactic-co-glycolic acid) nanoparticles were fully characterized in terms of their in vitro performance against breast adenocarcinoma cells. The successful incorporation of the drug within the hydrophobic matrix of nanoparticles was evidenced by a high loading efficiency (86\%) [69].

Besides their main characteristics of biocompatibility and biodegradability, biopolymers are considered to be an important alternative to synthetic polymers from an environmental point of view due to the fact that in their production, energy consumption and gas emissions are reduced.

Table 1 below presents examples of carrier-drug systems used in some studies.

Table 1. Carriers and drugs used in different studies.

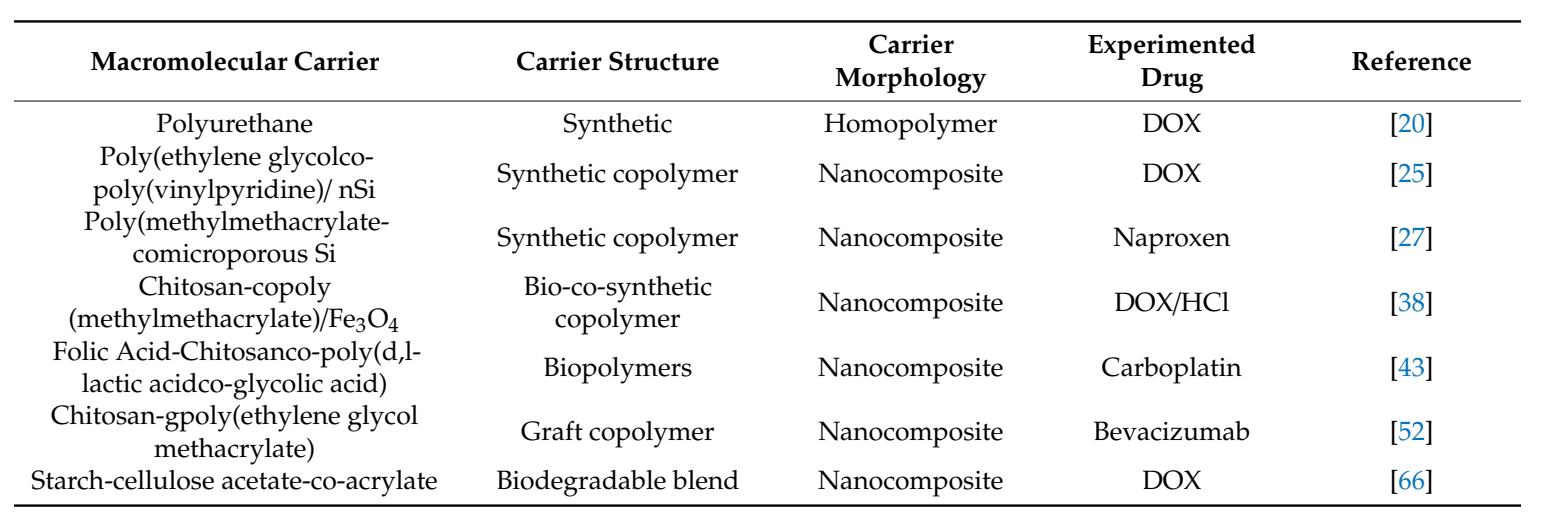

\section{Polymer Micelles}

Polymer micelles are an important group of drug carriers in chemotherapy treatments. 
The need for smart materials in the area of biotechnology has accelerated the development of stimuli-responsive copolymer micelles. To achieve the simultaneous delivery of chemotherapeutic drugs and gene agents, the carriers must be able to protect them from degradation and premature release. Micelleplexes consisting of amphiphilic block copolymers are made of interior hydrophobic blocks, with hydrophilic blocks forming the shell. The first ones act as a reservoir for poorly soluble hydrophobic drugs, and the hydrophilics mask the payloads.

A study has shown that the block copolymer adsorbed on a nanoparticle can acquire the structure of a micelle [70].

Redox-responsive core-crosslinked polymers were prepared by crosslinking mPEGylated starch (St) (mPEG-St) with 3,3'-dithiodipropionic acid (DPA), a crosslinker containing a disulfide bond. The (mPEG-St-DPA) micelles showed good stability, and a protein adsorption test indicated that the micelles were hemocompatible. In vitro release studies showed that DOX-loaded micelles exhibited enhanced release of DOX in the presence of glutathione. An in vitro MTT assay confirmed that the core-crosslinked mPEG-St-DPA micelles were biocompatible with HeLa cells and that DOX-loaded micelles displayed a higher inhibition of HeLa cell proliferation. The study suggested that the redox-responsive mPEG-St-DPA micelles hold great potential as ideal drug delivery carriers for cancer therapy [71].

To optimize nanosized micelles based on the PEG-PLA-PEG triblock copolymer, the effect of PLA on the physicochemical properties of micelles was studied. It was established that the loading amount of DOX encapsulated in micelles as well as the release of DOX from the micelles depended on the molecular weight (MW) of PLA. The triblock copolymers themselves did not show any toxicity over a wide range of concentration. DOX-loaded micelles killed more tumor cells than the free DOX [72].

Polymeric micelles consisting of hydrophobic polyethyleneimine and cis 1,2-cyclohexandycarboxylic anhydride were used to deliver drugs such as Candesartan and Paclitaxel (PTX) in the chemotherapy treatment of cervical cancer. The PTX-loaded micelles have great potential as a binary drug delivery system for efficient cancer therapy via synergism [73].

Other micelles based on a 1-pyrenemethanol-modified carboxymethyl CS conjugate with succinyl linkage were produced to regulate tumor extracellular $\mathrm{pH}$. This study provided a new strategy for the design of tumor extracellular $\mathrm{pH}$ nanocarriers for drug delivery [74].

An amphiphilic copolymer based on a PEG hydrophilic segment, an FA-targeting agent, a lysine (L) linker, and a polycaprolactone (PCL) hydrophobic segment was produced. The tests done revealed that the copolymer was practically nontoxic and that the obtained micelles have great potential for use in drug delivery [75].

A biocompatible and biodegradable diblock copolymer based on a PEG-poly(DL-lactide) micelle was prepared for the delivery of DTX to treat cervical cancer. The results of an in vitro study confirmed that such micelles could be used as a surfactant-free effective carrier for the delivery of DTX [76].

Poly[L-co- $N, N^{\prime}$-bis(acryloyl) cystamine-co-dodecylamine] nanomicelles (Nms) were synthesized through addition terpolymerization. DOX was loaded onto Nms for the investigation of its delivery. The Nms were biocompatible and biodegradable and could be potentially used as drug vehicles in controlled release [77].

Carbon quantum dots (Qds) are believed to play a key role in the field of targeted drug delivery [78]. The synthetic polymer $\dot{\alpha}, \beta$-poly(N-hydroxyethyl)-DL-aspartamide (PHEA) was functionalized with lipoic acid (LA) pendant moieties to obtain a synthetic derivative (PHEA-LA-PEG-FA) able to self-assemble in aqueous medium, giving rise to polymer micelles exposing their FA- and PEG-targeting groups. The drug-carrying ability of the copolymer micelles was studied along with the cytotoxicity of the obtained nanostructure, aiming at breast cancer cells employing DOX. The properties of the Au shell Qds incorporated in the micelles as cell imaging agents and a photothermal anticancer treatment tool were explored [79].

It was found that an ultrasensitive reduction-responsive polymeric spherical micelle based on a polytriphenylporphyrin polydisulfide ester as a porphyrin photosensitized delivery system in aqueous 
solution exhibited rapid and effective release of the porphyrin photosensitizer under an intracellular reductive atmosphere. The results of in vitro intracellular endocytosis and cytotoxicity validated that compared to the polymeric micelles, cellular uptake ability was enhanced, and antitumor efficiency was improved. Thus, as a photosensitizer delivery system, the copolymer showed promising potential applications in photodynamic cancer therapy, with excellent reductive responsiveness [80].

Block copolymer micelles made of PEG, dimethyl thioketal (DMTK), SS, and PLA (PEG-DMTKSS-PLA) were obtained, and their self-assembled redox and oxidative stress dual-responsiveness were studied, and they were proven to be promising as an efficient drug delivery system. The analyses were conducted with several cancer cells (cervix, lung, gastric, and colon) [81].

In a recent study, nanocarriers based on amphiphilic block copolymers with tailored temperatures and $\mathrm{pH}$ responsiveness were prepared. The hydrophilic blocks consisted of temperature-sensitive $\mathrm{N}$-isopropylacrylamide and $\mathrm{pH}$-sensitive units of 5-methacryloyloxy pentatonic acid or 4-methacryloyloxy benzoic acid, while the hydrophobic blocks were composed of n-hexyl acrylate or styrene. Some of these types of micelles may find applications as drug carriers [82].

DOX-mixed micelles for biotin-targeted drug delivery and enhanced photothermal/photodynamic therapy (PTT/PDT) and glutathione-mixed micelles were prepared from a polycaprolactone-disulfide bond-biodegradable photoluminescent polymer (PCL-SS-BPLP) and biotin PEG-cypate. Chemically linking cypate into the mixed micelles greatly improved cypate solubility and the PTT/PDT effect. The micelles also exhibited good monodispersity, stability in the cell medium ( 119.7 nm), low critical micelle concentration, good biodegradability, and resistance to photodecomposition. The designed biodegradable micelles showed promise as carriers for antitumor drug delivery and chemo/PTT/PDT combination therapy [83].

Multifunctional smart carriers, which can release their payload upon an external or internal stimuli such as $\mathrm{pH}$ or temperature, are proving to be major frontrunners in the development of effective strategies to combat cancer with minimal side effects. Among $\mathrm{pH}$-responsive polymers are PAA, poly(methacrylic acid), and poly( $N, N$ dimethyl aminoethyl methacrylamide). Temperature-response polymer micelles have been the most studied to date. They can be categorized according to either lower critical solution temperatures or upper critical solution temperatures. Other micelles are light-responsive or even multiresponsive [84].

Elastin-like polypeptide (ELP)-based self-assembling micelles with tethered gastrin-realizing peptide on the surface have been suggested to actively target prostate cancer cells. The poorly soluble drug DTX can be loaded into the hydrophobic cores of ELP micelles, but so far only limited drug retention times have been achieved. A novel type of drug nanocarrier was successfully applied to reduce the cell viability of prostate cancer cells in vitro through the specific delivery of DTX [85].

Micelles have recently been under intensive study due to their main properties, such as in vivo stability, drug protection, release kinetics, and ease of cellular penetration, which result in increased cancer therapeutic efficacy.

\section{Polymer Hydrogels and Nanogels}

The hydrophilic functional groups of polymer 3D networks become hydrated in aqueous media or in biological fluids, forming the hydrogels. Extensive application of these products in industrial and environmental areas is considered to be of prime importance.

Hydrogels have specific characteristics that make them applicable in some areas of medicine, such as sensors, tissue repair, drug carriers, and many others. Their main limitations are poor mechanical properties [86].

Hydrogels can be classified based on source (natural or synthetic), type of polymer (homopolymer, copolymer, multipolymer), morphology (amorphous, semicrystalline, crystalline), type of crosslinking, physical appearance, and electrical charge [87].

Hydrogels can be synthesized with or without crosslinking components. There are different techniques to obtain hydrogels without crosslinking agents, such as the following: 
- $\quad$ Through H bonds (example: PAA with PEG);

- $\quad$ From an amphiphilic graft and a block copolymer;

- $\quad$ With PLA and PEG;

- $\quad$ With poly(butylene terephthalate) and PEG;

- With hydrophobized polysaccharides and others [88].

Hydrogels are thermodynamically compatible with water, which allows them to swell. They are widely used in the pharmaceutical and medical fields, such as in biosensors, materials for contact lenses, synthetic skin, and lining for hearts. They can be used for 3D cell cultures and as drug delivery carriers. Hydrogels are efficient candidates for controlled release, bioadhesives, and/or targeted drug delivery, as they are able to encapsulate biomacromolecules, including proteins, DNA, and hydrophilic and hydrophobic drugs. Hydrogel-based platforms can be used in different ways for oral, rectal, ocular, epidermal, and subcutaneous applications [89].

Some hydrogels are formed by smart polymers, which are able to adjust their properties in response to factors such as temperature, $\mathrm{pH}$, and ionic strength. Among the smart polymers, thermoresponsive poly(N-isopropylacrylamide) is very important because of its well-defined structure and its temperature response, which is close to human body temperature: it can also be fine-tuned [90].

Hydrogels based on biopolymers (polysaccharides, proteins) are of great interest in drug delivery and tissue engineering. Cellulose, CS, and collagen are probably the most important, since they are the most abundant on earth and in the human body (collagen). Cellulose derivatives such as methylcellulose are ideal for the preparation of thermoresponsive hydrogels. The cationic character of CS favors the formation of gels through electrostatic interactions with sodium sulfate as a precipitant. Various hydrogels can be obtained from collagen, gelatin, and peptides [91].

The increase of the stability of CS in solution is very important for its application. This problem can be solved through hydrogelation. A CS hydrogel was readily prepared through the addition of $\mathrm{NaOH}$ solution to a CS acetic acid solution. In a wet state, the CS hydrogel was stable and could maintain its MW for long periods of time at room temperature. The CS hydrogel could be readily dissolved with the addition of organic acids [92].

The efficiency of an Na/CS/HAP hydrogel as a drug carrier with DOX for liver cancer was studied. DOX release, the effect of its concentration, as well as the amount of HAP in the drug release were investigated. The results showed that the drug release was $\mathrm{pH}$-sensitive and that the best release was at $\mathrm{pH} 5$ [93].

CS gel has fragility in some of its applications, and therefore it needs modification. One physicochemical change has been done by crosslinking sodium tripolyphosphate. In order to improve CS-based hydrogel properties, CS derivatives have been synthetized. The functional amino groups on CS macromolecules helped the polymer to participate in chemical reactions, which led to derivatives with improved characteristics such as mucoadhesion, high drug loading, and the ability to transfer genes. Some other chemical modifications have gained interest for the preparation of a photopolymerizable CS derivative or improvements to CS solubility in water [50].

It is worth noting the application of $\mathrm{pH}$-responsive hydrogels in ophthalmic cancer therapy. Ophthalmic drug delivery is an area that is seeing a significant impact in therapy from hydrogels [94].

The drug-releasing process of hydrogel membranes made of MWCNTs, PVA, PVP, and PEG, such as PVA/PVP/MWCNTs and PVA/PEG/MWCNTs, was investigated. A maximum degree of swelling was observed at $\mathrm{pH} 7$, and the swelling degree increased with the amount of MWCNTs. All hydrogel membranes followed non-Fickian mechanisms, and drug release was controlled by varying the amount of filler [95].

Crosslinking methacrylic acid with itaconic acid through ethylene glycol dimethacrylate was carried out to synthesize robust hydrogels for oral administration and tune them for the targeted release of 5FU and Leucovorin calcium in the colon. Swelling, drug loading, and drug release evaluations were carried out at two different $\mathrm{pH}$ levels. The hydrogels obtained were biocompatible and nontoxic as investigated in an oral toxicity study on rabbits [96]. 
Poly( $\varepsilon$-caprolactone-co-polydioxane)-b-PEG-b-( $\varepsilon$-caprolactone-co-polydioxane) triblock copolymer hydrogel has a semisolid morphology, is well-suited for the sustained delivery of hydrophilic macromolecular drugs, and shows the longest release period for hydrophobic drugs. Small molecular hydrophilic drugs such as Mitomycin C mainly aggregate in the loose hydrophilic shell of micelles, and given their low fluid mechanic radius, are released quickly through pore diffusion. In contrast, human serum albumin is released much slower because of its high hydrodynamic volume [97].

A biodegradable sol gel drug carrier made of an HA-Ca-AA hydrogel combining a hyaluronic acid-calcium complex (HA-Ca) and sodium alginate (AA-Na) components for the local sustained delivery of the drug Cyclosporine A was developed. An HA-Ca complex with a very high degree of substitution was prepared through the acid-base reaction of HA and Ca acetate. Gelation was completed within 2 to $45 \mathrm{~min}$ without the external addition of Ca salts, indicating the high potential of the hydrogel system for drug delivery through injection in vivo [98].

Porous silicon-based nanocomposite hydrogels were produced through the gelation of PEG double acrylate (PEGDA) macromers due to the initiation of singlet oxygen photosensitized with porous nSi under near-infrared (NIR) light irradiation. Multifunctional nSi/PEGDA nanocomposite hydrogels showed strong fluorescence, excellent biodegradability, significant photothermal effects, and sustained drug release with high efficiency $(>80 \%$.). The authors concluded that these types of hydrogels will have clinical significance in local clinical therapies in the future [99].

An application of a polyacrylamide-co-grafted-gum ghatti (a polysaccharide) copolymer for transdermal delivery of an antipsychotic drug (Quetiapine fumarate) triggered by electric stimulus was also explored [100].

Light-responsive hydrogels are promising potential applications in drug/gene delivery, microlenses, sensors, etc., due to the fact that the activation process via light can be remote and noninvasive. The hydrogel consists of a deoxycholic acid-modified B-cyclodextrin derivative and an azobenzene-branched-PAA copolymer and can be converted efficiently from gel to sol upon photoirradiation with light at a 355-nm wavelength. The hydrogel is able to recover from sol to gel upon photoirradiation with light at a 450-nm wavelength. The reversible transition of this hydrogel can be controlled under mild conditions, suggesting that this hydrogel may have a promising role in bioengineering applications for the release of molecular or cellular species. A novel light-responsive hydrogel was made from a poly(isopropyl acrylamide) nanocomposite incorporating glycidyl methacrylate-functionalized graphene oxide [101].

Nanogels possess the features of hydrogels and nanoparticles. They have attracted much attention in the last two decades due to the combined properties of nanotechnology and crosslinking gel-like materials. They have shown great biocompatibility and biodegradability in both in vitro and in vivo studies and have been widely used in biomedical science in the areas of imaging, diagnosis, drug delivery, tissue engineering, biosensors, etc. Their sizes, shapes, charges, and surface chemistries can be easily tuned, which offers nanogels many advantages as nanocarriers in the delivery of small molecules, proteins, genes, and other therapies [102].

Nanogels are three-dimensional network nanostructures composed of functional polymers. Their size is in the range of 10-1000 nm. They present numerous advantages, such as water solubility, high water content, and, as already mentioned, biocompatibility [103].

Due to their porosity, nanogels are able to encapsulate drugs and release them in a controlled manner. Internal and external factors such as $\mathrm{pH}$, magnetic field, temperature, enzyme, and light can stimulate the response of nanogels and are useful in the controlled release of bioactive agents [104].

One article has reviewed related subjects such as nanogel assimilation in nanomedicine, features and their advantages, and recent progress in nanogels as drug carriers [105].

Nanogels can also be defined as highly crosslinked nanosized hydrogels ranging from 20 to $200 \mathrm{~nm}$. Nanogels have been developed to deliver drugs to treat a range of diseases, including cancer, autoimmune disorders, and neurodegenerative conditions. They can be administered through various routes, including oral, pulmonary, nasal, parenteral, and intraocular routes [106]. 
Copolymers containing PEG, maleimide, and pendant hydroxyl groups as side chains are often used to produce nanogels [107].

The shift from mono- to dual- and then to multistimuli-responsive polymers, including hydro- and nanogels, has increased confidence in their ability to deliver drugs intracellularly while overcoming the problems associated with mono- and dual-responsive products. The sensitivity of these macromolecules to multiple stimuli makes them quite versatile and increases their applicability [108].

Polymer nanogels are able to efficiently encapsulate therapeutics of diverse sizes and natures through simple mechanisms. One review analyzed the use of extracellular $\mathrm{pH}$-targeting for nanogel nSiRNA delivery and PEGylated nanogels for improved cancer therapies [109].

Semi-interpenetrating nanohybrid hydrogels made of poly(N-isopropylacrylamide)/CS/MWCNTs were prepared. They showed temperature and $\mathrm{pH}$ dual-responsiveness, and a hydrogel containing MWCNTs- $\mathrm{COOH}$ possessed high swelling ratios. The researchers considered that these designed nanogels could be used for the size-specific target delivery of anticancer drugs [110].

A positively charged nanogel was synthesized to inhibit the proliferation of breast cancer cell lines. A model drug, 10-hydroxycamptothecin (HCPT), was trapped in the core via facile diffusion to form $\mathrm{CS} / \mathrm{HCPT}$. Its characteristics were evaluated by assessing particle size, drug loading quantity, and loading efficiency. Furthermore, the cell internalization, cytotoxicity, and apoptosis of CS/HCPT were also investigated in vitro. The research indicated that the positively charged CS-based nanogels could be used as a drug delivery agent [111].

A thermo/pH/magnetic triple-sensitive nanogel based on poly( $\mathrm{N}$-isopropyl acrylamide), poly(N-dimethylaminoethyl methacrylate), and magnetic graphene oxide was synthesized. In vitro cytotoxicity studies showed that the obtained nanogel had low cytotoxicity and good biocompatibility and could reduce the cytotoxicity of DOX [112].

An approach was presented for the synthesis of thermoresponsive and $\mathrm{pH}$-sensitive magnetic nanogels by using the biodegradable starch maleate as a crosslinker and a magnetic nanoparticle stabilizer. Chemically modified starch maleate produced highly stable $\mathrm{Fe}_{3} \mathrm{O}_{4}$ magnetic nanoparticle aqueous dispersion. Then, $\mathrm{N}$-isoptopylacrylamide and itaconic acid were successfully copolymerized to prepare the thermo- and $\mathrm{pH}$-responsive magnetic nanohydrogels. Drug loading was examined along with other tests, with Mitoxantrone as an anticancer drug. The results confirmed the low toxicity and enhanced anticancer effect of the drug-loaded magnetic nanogels [113].

A biocompatible nanogel based on glycogen and 2-hydroxy ethyl methacrylate using an ethylene glycol dimethacrylate crosslinker was produced. Mesoporous silica was used as a template. The nanogel was shown to effectively load the 5FU drug. An intercellular release experiment demonstrated that 5FU-loaded nanogel could efficiently kill MG-63 cancer cells [114].

Functionalized biocompatible disulfide nanogel on the basis of $N, N^{\prime}$-di-(tert butoxy carbonyl) cysteine-crosslinked magnetite PEG containing FA was synthesized. For this purpose, star-shaped PEG coupled with amino silane was grafted onto $\mathrm{Fe}_{3} \mathrm{O}_{4}$ nanoparticles. L-cystine amino acid was used to crosslink two free hydroxyl groups of PEG to produce the desired redox-sensitive disulfide nanogel $5 \mathrm{FU}$ as a drug. The structure of the nanogel was designed so that the toxic active drugs could be released only inside the targeted cells after a controlled time. The produced nanogel demonstrated specific targeting of FA receptor-positive cells [115].

In the development of a tumor targeting $\mathrm{pH}$-responsive and enzymatically degradable crosslinked fluorescent nanogels made of boronic acid-conjugated lactose-modified CS (chitlac-BOH) and dopamine, nitric oxide-conjugated partially carbonized HA for DOX loading was reported. Carbonized HA and NO were released from DOX-loaded fluorescent nanogels due to the $\mathrm{pH}$-dependent cleavage of anticancer agent loading. The system used tumor-targeting HA to deliver DOX and NO within cancer cells, while tracking was performed [116].

Various specially designed copolymers, such as poly( $\mathrm{N}$-isopropylacrylamide-co-acrylic acid) nanogels with different molar compositions, were synthesized and evaluated as carriers for drug 
delivery. After testing, $\mathrm{DOX}-\mathrm{HCl}$ presented excellent dispersibility in physiological environments (pH 7.4 and 5 at $37^{\circ} \mathrm{C}$ ).

Their release behavior coupled with their size and low cytotoxicity makes these nanogels good carriers in cancer therapies based on an enhanced permeability and retention effect with drug $\mathrm{pH}$-triggered release after endocytosis in tumor cells [11].

It was shown that the therapeutic efficacy of thermoresponsive nanogels as protein carriers was triggered by a decrease in temperature. The authors of the research envisioned the use of such thermal triggers as being relevant for the treatment of superficial tumors, in which the induction of apoptosis can be controlled through the application of local cooling agents [117].

Temperature- and $\mathrm{pH}$-sensitive core-shell nanogels were synthesized based on $\mathrm{N}$-isopropylacrylamide and methacryloxy benzoic acid and PEG (core) as a crosslinker. With the use of another crosslinker, such as 9-divynil-2,4,8,10 tetraoxaspirol (5,5')-undecane (DVA), the nanogels were reduced in size to around $100 \mathrm{~nm}$. The empty nanogels were biocompatible with a lung cancer cell line (NCl H1437), while the DOX-loaded DVA-crosslinked nanogels resulted in efficient cytotoxicity for that cell line [118].

Hydrogels and nanogels offer a versatile platform for the therapy of several diseases, particularly cancers. With subtle improvements, they could become exceptional drug delivery vehicles. Their main characteristics are biocompatibility, biodegradability, high drug loading capacity, and colloidal stability. It is also important to know that some are double- and triple-stimuli sensitive.

\section{Polymersomes and Liposomes}

Natural cells possess membranes formed by amphiphilic macromolecules. In an effort to mimic and improve these structures and exploit them for research diagnostic and therapeutic purposes, polymersome technology was born. Polymersomes are vesicle membranes made of amphiphilic synthetic block copolymers. They are self-assembled structures. Polymersomes have attracted much attention as versatile carriers due to their tunable membrane properties and ability to encapsulate or integrate a broad range of drugs. A long blood circulation time can be accomplished when PEG is used as a component of the block copolymer membrane, which contributes to good responses to various internal or external stimuli [119].

A recent documented review underlined the fact that the fundamental importance of cell membranes has incited scientists to not only study them but also to create synthetic analogs and models (such as bilayer structures based on natural or synthetic components ranging from lipids to surfactant) and amphiphilic block copolymers.

Liposomes (phospholipid vehicles) can also be used as carriers for the administration of drugs [120].

Compared to liposomes, polymersomes have broader possibilities for tuning their characteristics, such as biodegradability, biocompatibility, and other possibilities. Polymer vesicles (besides the differences already mentioned) have been proven to be more robust and less water-permeable compared to liposomes. Among the biomedical applications, drug/gene delivery holds the most promise due to low critical aggregation, concentration, and robustness in the bilayer. Ideal polymersomes should release the drug at the target site in a controllable manner. Hence, the polymersome building blocks have to be responsive to external or internal stimuli [121].

Polymersomes are increasingly being used as platforms for simultaneous drug delivery and imaging and are therefore becoming popular theranostic products. Examples of polymersome block copolymers are poly(acrylic acid-co-distearate acrylate), the poly(trimethylene carbonate)-co-poly(Lglutamic acid) copolymer, polybutadiene-b-PEO (PB-b-PEO), poly(ethyl ethylene)-b-PEO (PEE-b-PEO), and PS-b-PEO [119,122].

The use of nanoparticles as tumor-targeting agents is steadily increasing, and the influence of their characteristics (size, stealth) has been established. However, not much is known about the impact of tumor presence on nanocarrier circulation times. A study reported on the influence of tumor presence on in vivo circulation time and the biodistribution of polybutadiene-co-poly (ethylene oxide) polymersomes. In the study, the polymersomes were loaded with gamma emitter and administered 
intravenously, followed by timed ex vivo biodistribution. A large reduction in circulation time was observed in tumor-bearing mice. Pretreatment with chlodronate liposomes depleted macrophages in the spleen and liver and restored the circulation time of the polymersomes, with no significant difference in circulation time between healthy mice and tumor-bearing mice pretreated with clodronate liposomes [123].

Polymersomes are able to encapsulate large amounts of multiple drugs with both hydrophilic and hydrophobic properties simultaneously, and they also offer a mechanism to combat multidrug-resistant cancers and poor patient tolerance of the cytotoxic compounds used. Researchers have reported the formulation and evaluation of a novel electroneutral polymersome capable of high encapsulation efficacies in multiple drugs (DOX, 5-FU, and Leucovorin). In vivo biodistribution of the polymersomes was established and was found to accumulate largely in tumor tissue. The encapsulation of the three drugs was assessed both in vitro and in vivo and compared to the same concentration of the three drugs in solution. A higher efficacy and higher maximum tolerance dose for the combination drug-loaded polymersomes was reported [124].

Polymersomes along with a series of copolymers employed for their preparation and potential applications as drug carriers were recently reviewed [125].

To achieve simultaneity in the case of liposome delivery, as in other carriers, the contents must be protected from possible degradation, and premature release must be prevented [70].

There are spherical lipid vehicles composed of one or more phospholipid bilayers and an aqueous internal cavity. They can be classified as uni-, oligo-, or multilamellar vesicles depending on the number of membrane bilayers, and they are formed through the self-assembly of phospholipids in contact with hydrophilic medium. This behavior increases their solubility in the medium and decreases their surface-to-volume ratio. Liposomes can be prepared through reverse-phase evaporation, the injection of phospholipids dissolved in an organic phase into a drug-containing aqueous phase, detergent dialysis, microfluidic hydrodynamic focus, supercritical reverse-phase evaporation, electroformation, microfluid liposome formation, and thin lipid film formation [126].

Liposomes as carrier systems have been explored more than other systems as a result of their various forms. Phospholipid bilayer membranes can generate spherical structures with an internal hydrophilic compartment through the introduction of phospholipids in water solution. They are biocompatible and biodegradable, and they are able to encapsulate and deliver both hydrophilic and hydrophobic agents in an afflictive way [127].

Their platforms have attracted considerable attention from academic and clinical areas and have become the most studied biomaterial nanoparticles due to the fact that they can improve the efficiency of a drug by increasing its solubility, overcoming resistance, controlling its targeted release, and modifying its biocompatibility, bioavailability, and safety profile [128].

Phosphatidylcholine, phosphatidylglycerol, and phosphatidylethanolamine are the components of different liposomes.

The drug Carboplatin was encapsulated into a liposome made of lecithin, cholesterol, and PEG through a reverse-phase evaporation technique, and its efficacy on lung cancer in vitro was evaluated. The study indicated that liposomes can be used for carboplatin delivery in lung cancer [129]. The same technique was used to prepare cis-platin-loaded PEGylated liposomes targeted with FA and evaluate their efficacy in a liver cancer cell line. The results of this research confirmed the potency of targeted PEGylated liposomal nanoparticles [130].

Liposomes consist of a region of aqueous solution inside a hydrophobic membrane. Hydrophobic chemicals can be easily dissolved into the lipid membranes: in this way, liposomes are able to carry both hydrophilic and hydrophobic molecules, while the location of the drug depends upon its physiochemical characteristics and the composition of the lipid. For the delivery of necessary drugs to the site of the tumor, the lipid bilayers fuse with other bilayers of the cell (cell membrane) to release the liposomal content. The steps involved in liposome drug delivery are adsorption, endocytosis, fusion, and lipid exchange. Once the anticancer drugs are released, the cancer cells are killed [131]. 
Although polymersomes and liposomes possess amphiphilic characteristics, they are different from a properties point of view. Polymersomes are tougher, malleable, and more stable: liposomes, on the other hand, are closer mimics of natural cell membranes, and they are more difficult to handle and use.

Table 2 shown below presents other carrier and drugs for cancer therapies.

Table 2. Carriers and drugs used in different studies.

\begin{tabular}{|c|c|c|c|c|}
\hline Macromolecular Carrier & Carrier Structure & $\begin{array}{c}\text { Carrier } \\
\text { Morphology }\end{array}$ & $\begin{array}{l}\text { Experimented } \\
\text { Drug }\end{array}$ & Reference \\
\hline $\begin{array}{c}\text { mPoly(ethylene glycol)- } \\
\text { Starch-dithiopropionicacid }\end{array}$ & $\begin{array}{l}\text { Core cross-linked } \\
\text { polymers }\end{array}$ & Micelles & DOX & [71] \\
\hline $\begin{array}{l}\text { Poly(ethylene glycol)-copoly(lactic } \\
\text { acid)-co-Poly(ethylene glycol }\end{array}$ & Triblock copolymer & Micelles & DOX & [72] \\
\hline Poly(ethylene glycol-copoly(d,l-lactide) & Diblock copolymer & Micelles & DTX & [76] \\
\hline Sodium/chitosan/hydroxyl apatite & Nanocomposite & Hydrogel & DOX & [93] \\
\hline Hyaluronic acid-calcium-Algae & Nanocomposite & Hydrogel & Cyclosporine A & [98] \\
\hline Chitosan & Biopolymer & Nanogel & HCPT & [111] \\
\hline $\begin{array}{c}\mathrm{N} \text {-isopoptylacrylamide-co-itaconic } \\
\text { acid } / \mathrm{Fe}_{3} \mathrm{O}_{4}\end{array}$ & Copolymer & Nanogel & Mitoxantrone & [113] \\
\hline Lecitine-cholesterolpoly(ethylene glycol) & Polymer blend & Liposome & Carboplatin & [130] \\
\hline
\end{tabular}

\section{Conclusions}

The results of the studies done and presented in this review could lead to new ideas for the improvement of cancer drug carriers: they are a strong impulse for the continuation of research in this area.

Many of the polymer systems mentioned above are replacing conventional drug delivery platforms due to their main characteristics, such as the lack of side effects and minimized damage to healthy cells. The application of external or internal stimuli is highly recommended for cancer treatments.

Funding: This research received no external funding.

Conflicts of Interest: The author declares no conflicts of interest.

\section{Abbreviations}

$\begin{array}{ll}\text { AA } & \text { Algae, alginate } \\ \text { ART } & \text { Artenisimin drug } \\ \text { AS } & \text { Alphastatin drug } \\ \text { b } & \text { Block (for copolymer) } \\ \text { BPLP } & \text { Biodegradable photoluminescent polymer } \\ \text { co } & \text { (For copolymer) } \\ \text { CA } & \text { Candesartan drug } \\ \text { CPP } & \text { Cyclocarya paliurus polysaccharide } \\ \text { CS } & \text { Chitosan } \\ \text { CSC } & \text { Cancer stem cell } \\ \text { CUR } & \text { Curcumin } \\ \text { DGMNs } & \text { Dextran goldmag nanoparticles } \\ \text { DMTK } & \text { Dimethylthiotekal } \\ \text { DNA } & \text { Deoxyribonucleic acid } \\ \text { DOX } & \text { Doxorubicyn or Addryamicine drug } \\ \text { DPA } & 3,3^{\prime} \text { didithiodipropionic acid } \\ \text { DTX } & \text { Docetaxel drug } \\ \text { DVA } & 9 \text { divinyl-2,4,6,8,10-tetraoxispirol-(5,5') undecane } \\ \text { ELP } & \text { Elastin-like polypeptide } \\ \text { FA } & \text { Folic acid } \\ \text { FU } & \text { Fluorouracil drug } \\ \text { GM } & \text { Goldmag (Au/Fe } \mathrm{O}_{4} \text { ) } \\ \text { GRP } & \text { Gastrin-releasing peptide } \\ & \end{array}$




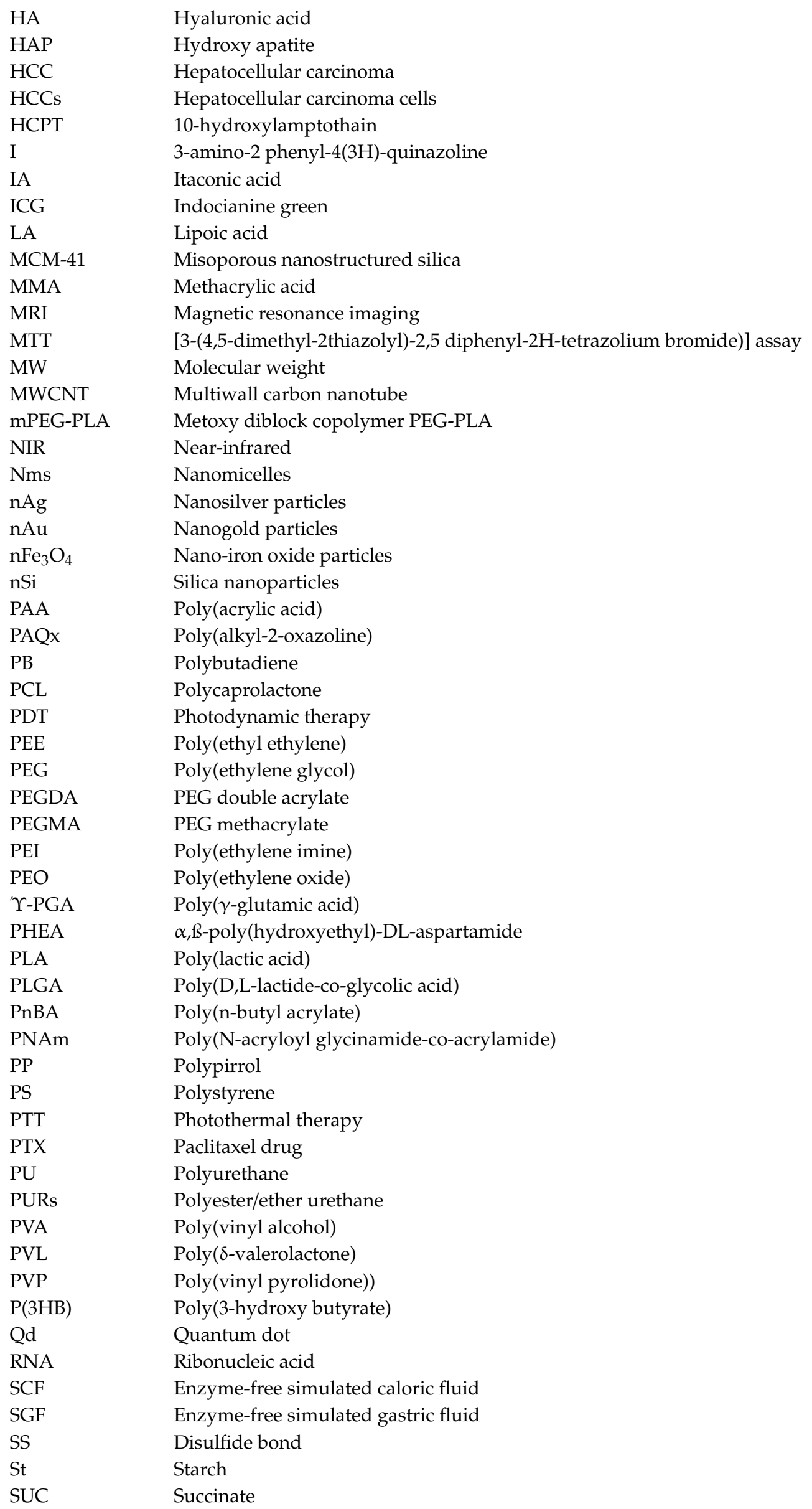




\section{References}

1. Chaudhary, Z.; Ahmed, N.; ur Rehman, A.; Khan, G.M. Lipid polymer hybrid carrier systems for cancer targeting: A review. Int. J. Polym. Mater. Polym. Biomater. 2018, 67, 86-100. [CrossRef]

2. Siegel, R.I.; Miller, K.D.; Jemal, A. Cancer Statistics 2019. CA Cancer J. Clin. 2019, 69, 7-34. [CrossRef]

3. Li, N.; Zhao, L.; Qi, L.; Li, Z.; Luan, Y. Polymer assembly: Promising carriers as co-delivery systems for cancer therapy. Prog. Polym. Sci. 2016, 58, 1-26. [CrossRef]

4. Thakur, S.; Pramod, K.S.; Malviya, R. Utilization of Polymeric Nanoparticle in Cancer Treatment. A Review. J. Pharm. Care Health Syst. 2017, 4. [CrossRef]

5. Seifu, M.F.; Nath, L.K. Polymer drug conjugates; Novel carrier for cancer chemotherapy. Polym. Plast. Technol. Mater. 2019, 58, 158-171. [CrossRef]

6. Wagner, A.M.; Spencer, D.S.; Peppas, N.A. Advanced architectures in the design of responsive polymers for cancer nanomedicine. J. Appl. Polym. Sci. 2018, 135. [CrossRef]

7. Patra, A.; Satpathy, S.; Shenoy, A.K.; Bushy, J.A.; Kazi, M.; Hussain, M.D. Formulation and evaluation of mixed polymeric micelles of quercetin for treatment of breast, ovarian, and multidrug resistant cancers. Int. J. Nanomed. 2018, 13, 2809-2881.

8. Sabzichi, M.; Hamishehkar, H.; Ramezani, F.; Sharifi, S.; Tabasinezhad, M.; Pirouzpanah, M.; Ghanbari, P.; Samadi, N. Luteolin-loaded phytosomes sensitive human breast carcinoma MDA-MB 231 cells to Doxorubicin by suppresing Nrf2 mediated signalling. Asian Pac. J. Cancer Prev. 2014, 15, 5311-5316. [CrossRef]

9. Kumar, S.; Sarita, N.M.; Dilbaghi, N.; Tankeshwar, K. Recent advances and remaining challenges for polymeric nanocomposites in healthcare applications. Prog. Polym. Sci. 2018, 80, 1-38. [CrossRef]

10. Honey, P.G.; Rijo, J.; Anju, A.; Anoop, K.R. Smart polymers for the controlled delivery of drugs-A concise overview. Acta Pharm. Sin. B 2014, 4, 120-127.

11. Cuggino, J.C.; Molina, M.; Wedepohl, S.; Igarzabal, C.I.A.; Calderon, M.; Gugliotta, L.M. Responsive nanogels for application as smart carriers in endocytic $\mathrm{pH}$-triggered drug delivery system. Eur. Polym. J. 2016, 78, 14-24. [CrossRef]

12. Carraher, C.E., Jr.; Roner, M.R.; Campbell, A.G.; Moric-Johnson, A.; Miller, L.; Slawek, P.; Mosca, F. Group IVB metallocene polyesters containing camphoric acid and preliminary cancer cellactivity. Int. J. Polym. Mater. Polym. Biomater. 2018, 67, 469-479. [CrossRef]

13. Zou, H.; Liu, H. Synthesis of thermal and photo dual-responsive amphiphilic random copolymer via atom transfer radical polymerization and its control release of doxorubicin. Int. J. Polym. Mater. Polym. Biomater. 2017, 66, 955-962. [CrossRef]

14. Massoumi, B.; Poorgholy, N.; Jaymand, M. Multistimuli responsive polymeric nanosystems for theranostic applications. Int. J. Polym. Mater. Polym. Biomater. 2017, 66, 38-47. [CrossRef]

15. Din, F.U.; Aman, W.; Ullah, I.; Qureshi, O.S.; Mustapha, O.; Shafique, S.; Zeb, A. Effective use of nanocarriers as drug delivery system for the treatment of selected tumors. Int. J. Nanomed. 2017, 12, 7291-7309. [CrossRef]

16. Li, L.; Yang, W.-W.; Xu, D.-G. Stimuli-responsive nanoscale drug delivery systems for cancer therapy. J. Drug Target. 2019, 27, 423-433. [CrossRef]

17. Mattu, C.; Silvestri, A.; Wang, T.R.; Boffito, M.; Ranzato, E.; Cassino, C.; Ciofani, G.; Ciardelli, G. Surface functionalized polyurethane nanoparticles for targeted cancer therapy. Polym. Int. 2016, 65, 770-779. [CrossRef]

18. Orum, S.M.; Demircoglu, Y.S. One-pot synthesis and characterization of crosslinked polyphosphazene dopamine microspheres for controlled drug delivery applications. J. Macromol. Sci. Part A 2019. [CrossRef]

19. Khan, M.A.; Raza, A.; Ovais, M.; Sohail, M.F.; Ali, S. Current state and prospects of nano-delivery systems for sorafenib. Int. J. Polym. Mater. Polym. Biomater. 2018, 67, 1105-1115. [CrossRef]

20. Huang, D.; Zhou, Y.; Xiang, Y.; Shu, M.; Chen, H.; Yang, B.; Liao, X. Polyurethane/doxorubicin nanoparticles based on electrostatic interactions as $\mathrm{pH}$-sensitive drug delivery carriers. Polym. Int. 2018, 67, 1186-1193. [CrossRef]

21. Liang, P.; Wang, C.-Q.; Chen, H.; Zhuo, R.-X.; Cheng, S.-X. Multi-functional heparin-biotin/heparin/calcium phosphate nanoparticles for targeted co-delivery of gene and drug. Polym. Int. 2015, 64, 647-653. [CrossRef]

22. Di Mascolo, D.; Basnett, P.; Palange, A.L.; Francardi, M.; Roy, I.; Decuzzi, P. Tuning core hydrophobicity of spherical polymeric nanoconstructs for docetaxel delivery. Polym. Int. 2016, 65, 741-746. [CrossRef] 
23. Li, X.; Kono, K. Functional dendrimer-gold nanoparticle hybrids for biomedical applications. Polym. Int. 2018, 67, 840-852. [CrossRef]

24. Lipowska-Kur, D.; Szweda, R.; Trzebicka, B.; Dworak, A. Preparation and characterization of doxorubicin nanocarriers based on thermoresponsive oligo(ethylene glycol) methyl ether methacrylate polymer-drug conjugates. Eur. Polym. J. 2018, 109, 391-401. [CrossRef]

25. Pourjavadi, A.; Tehrani, Z.M.; Bennett, C. PEG-co-poly (vinyl pyridine) coated magnetic mesoporous silica nanoparticles for $\mathrm{pH}$-responsive controlled release of Doxorubicin. Int. J. Polym. Mater. Polym. Biomater. 2015, 64, 570-577. [CrossRef]

26. Pourjavadi, A.; Tehrani, Z.M. Poly(N-isopropylacrylamide)-coated $\beta$-cyclodextrin-capped magnetic mesoporous silica nanoparticles exhibiting thermal and $\mathrm{pH}$ dual response for triggered anticancer drug delivery. Int. J. Polym. Mater. Polym. Biomater. 2017, 66, 336-348. [CrossRef]

27. Rafi, A.A.; Fakheri, F.; Mahkam, M. Synthesis and preparation of new $\mathrm{pH}$-sensitive nanocomposite based on MCM-41/poly(methacrylic acid ) as drug carriers. Polym. Bull. 2016, 73, 2649-2659. [CrossRef]

28. Su, T.; Cheng, F.; Lin, S.; Xiao, T.; Zhu, Y.; Cao, J.; He, B. Reduction-induced decomposition and self-aggregation strategy to induce reactive oxygen species for cancer therapy. ACS Appl. Biomater. 2018, 1, 954-960. [CrossRef]

29. Yuan, S.; Wu, M.; Han, L.; Song, Y.; Yuan, S.; Zhang, Y.; Wu, Z.; Qi, X. Surface partially neutralized dendtric polymer demonstrating proton-triggered self-assembled aggregation for tumor therapy. Eur. Polym. J. 2018, 103, 59-67. [CrossRef]

30. Bonadies, I.; Maglione, L.; Ambrogi, V.; Paccez, J.D.; Zerbini, L.F.; de Silva, L.F.R. Electrospun core/shell nanofibers as designed devices for efficient Artemisinin delivery. Eur. Polym. J. 2017, 89, 211-220. [CrossRef]

31. Zaaeri, F.; Khoobi, M.; Rouini, M.; Javar, H.A. pH -responsive polymer in a core-shell magnetic structure as an efficient carrier for delivery of doxorubicin to tumor cells. Int. J. Polym. Mater. Polym. Biomater. 2018, 67, 967-977. [CrossRef]

32. Palao-Suay, R.; Gomez-Mascaraque, L.G.; Aguilar, M.R.; Vazquez-Lasa, B.; San Roman, J. Self-assembling polymer systems for advanced treatment of cancer and inflammation. Prog. Polym. Sci. 2016, 53, 207-248. [CrossRef]

33. Saravanakumar, K.; Ali, D.M.; Kathiresan, K.; Wang, M.H. Antimicrobial, anticancer drug carrying properties of biopolymers-based nanocomposites-a mini review. Curr. Pharm. Des. 2018, 24, 3859-3866. [CrossRef]

34. Mousa, M.H.; Dong, Y.; Davies, I.J. Recent advances in bionanocomposites; preparation, properties and applications. Int. J. Polym. Mater. Polym. Biomater. 2016, 65, 225-254. [CrossRef]

35. Sionkowska, A. Biopolymeric nanocomposites for potential biomedical applications. Polym. Int. 2016, 65, 1123-1131. [CrossRef]

36. Li, M.; Ding, J.; Tao, Y.; Shi, B.; Chen, J.-H. Polysaccharides for biomedical applications. Int. J. Polym. Sci. 2019, 7841836. [CrossRef]

37. Mittal, H.; Ray, S.S.; Kaith, B.S.; Bathia, J.K.; Sukriti Sharma, J.; Alhassan, S. Recent progress in the structural modification of chitosan for application in diversified biomedical fields. Eur. Polym. J. 2018, 109, 402-434. [CrossRef]

38. Zarouni, M.; Salehi, R.; Akbazardeh, A.; Samadi, N.; Davaran, S.; Ramezani, F.; Dariushnejad, H. Biocompatible polymer coated paramagnetic nanoparticles for Doxorubicin delivery: Synthesis and anticancer effects against human breast cancer cells. Int. J. Polym. Mater. Polym. Biomater. 2015, 64, 718-726. [CrossRef]

39. Sun, L.; Chen, Y.; Zhou, Y.; Guo, D.; Fan, Y.; Guo, D.; Fan, Y.; Guo, F.; Zheng, Y.; Chen, W. Preparation of 5-fluorouracil-loaded chitosan nanoparticles and study of the sustained release in vitro and in vivo. Asian J. Pharm. Sci. 2017, 12, 418-423. [CrossRef]

40. Gooneh-Farahani, S.; Naimi-Jamal, M.R.; Naghib, S.M. Stimuli-responsive graphene-incorporated multifunctional chitosan for drug delivery applications;a review. Expert Opin. Drug deliv. 2019, 16, 79-99. [CrossRef]

41. Debnath, D.; Lee, Y.; Geckeler, K.E. Biocompatible polymers as a tool for the synthesis of silver nanoparticles: Size tuning and in vitro cytotoxicity study. Polym. Int. 2017, 66, 512-520. [CrossRef]

42. Salahuddin, N.; Elbarbary, A.A.; Alkabes, H.A. Antibacterial and anticancer activity of loaded quinazolinone polypyrrole/chitosan /silver chloride nanocomposite. Int. J. Polym. Mater. Polym. Biomater. 2017, 66, 307-316. [CrossRef] 
43. de Moraes Profirio, D.; Pessine, F.B.T. Formulation of functionalized PLGA nanoparticles with folic acid-conjugated chitosan for carboplatin encapsulation. Eur. Polym. J. 2018, 108, 311-321. [CrossRef]

44. Garcia-Couce, J.; Bada-Rivero, N.; Hernandez, O.D.L.; Nogueira, A.; Caracciolo, P.C.; Abraham, G.A.; Hernández, J.A.R.; Peniche, C. Dexamethasone-loaded chitosan beades coated with a pH dependent interpolymer complex for colon specific drug delivery. Int. J. Polym. Sci. 2019, 2019, 4204375. [CrossRef]

45. Amin, A.; Kandil, H.; Awad, H.M.; Ismail, M.N. Preparation and characterization of chitosan-hydroxyapatite-glycopolymer/Cloisite $30 \mathrm{~B}$ nanocomposite for biomedical applications. Polym. Bull. 2015, 72, 1497-1513. [CrossRef]

46. Prusty, K.; Swain, S.K. Nanostructured chitosan composites for cancer therapy: A review. Int. J. Polym. Mater. Polym. Biomater. 2018, 67, 879-888. [CrossRef]

47. Cao, Z.; Wang, X.; Cheng, X.; Wang, J.; Tang, R. In vitro and in vivo antitumor study of folic acid-conjugated carboxymethyl chitosan and phenylboronic acid-based nanoparticles. Int. J. Polym. Mater. Polym. Biomater. 2017, 66, 495-506. [CrossRef]

48. Zhang, L.; Hu, Y. Alphastatin-loaded chitosan nanoparticle preparation and its antiangiogenic effect on lung carcinoma. Int. J. Polym. Sci. 2019, 2019. [CrossRef]

49. Chang, P.-H.; Sekine, K.; Chao, H.-M.; Hsu, S.-H.; Chern, E. Chitosan promotes cancer progression and stem cell properties in association with Wnt signaling in colon and hepatocellular carcinoma cells. Sci. Rep. 2017, 7. [CrossRef]

50. Sugita, P.; Ambarsari, L. Lidiniyah, Optimization of ketoprofen-loaded chitosan nanoparticle ultrasonication process. Procedia Chem. 2015, 16, 673-680. [CrossRef]

51. Lee, E.; Park, S.J.; Lee, J.H.; Kim, M.S.; Kim, C.-H. Preparation of chitosan-TPP nanoparticles and their physical and biological properties. Asian J. Pharm. Sci. 2016, 11, 166-167. [CrossRef]

52. Savin, C.-L.; Popa, M.; Delaite, C.; Costuleanu, M.; Costin, D.; Peptu, C.A. Chitosan grafted-poly (ethylene glycol) methacrylate nanoparticles as carrier for controlled release of bevacizumab. Mater. Sci. Eng. C 2019, 98, 843-860. [CrossRef] [PubMed]

53. He, Z.; Lv, F.; Gan, Y.; Gu, J.; Que, T. Anticancer effects of Cyclocarya paliurus polysaccharide (CPP) on thyroid carcinoma in vitro and in vivo. Int. J. Polym. Sci. 2018, 2768120. [CrossRef]

54. Raveendran, R.; Mullen, K.M.; Wellard, R.M.; Sharma, C.P.; Hoogenboom, R.; Dargaville, T.R. Poly(2-oxazoline) block copolymer nanoparticles for curcumin loading and delivery to cancer cells. Eur. Polym. J. 2017, 93, 682-694. [CrossRef]

55. Saikia, C.; Das, M.K.; Ramteke, A.; Maji, T.K. Controlled release of curcumin from thiolated starch-coated iron oxide magnetic nanoparticles: An in vivo evaluation. Int. J. Polym. Mater. Polym. Biomater. 2017, 66, 349-358. [CrossRef]

56. Lachowicz, D.; Karabasz, A.; Bzowska, M.; Szuwarzynski, M.; Karewicz, A.; Nowakowska, M. Blood-compatible, stable micelles of sodium alginate-curcumin bioconjugate for anti-cancer applications. Eur. Polym. J. 2019, 113, 208-219. [CrossRef]

57. Song, Z.; Zhu, W.; Yang, F.; Liu, N.; Feng, R. Preparation, characterization, in vitro release and pharmacokinetic studies of curcumin-loaded mPEG-PVL nanoparticles. Polym. Bull. 2015, 72, 75-91. [CrossRef]

58. Petrov, P.D.; Yoncheva, K.; Gancheva, V.; Konstantinov, S.; Trzebicka, B. Multifunctional block copolymer nanocarriers for co-delivery of silver nanoparticles and curcumin: Synthesis and enhanced efficacy against tumor cells. Eur. Polym. J. 2016, 81, 24-33. [CrossRef]

59. Medel, S.; Syrova, Z.; Kovacik, L.; Hrdy, J.; Hornacek, M.; Jager, E.; Hruby, M.; Lund, R.; Cmarko, D.; Stepanek, P.; et al. Curcumin-bortezomib loaded polymeric nanoparticles for synergistic cancer therapy. Eur. Polym. J. 2017, 93, 116-131. [CrossRef]

60. Spiridov, A.P.; Osminkina, L.A.; Kharin, A.Yu.; Gongalsky, M.B.; Kargina, J.V.; Kudryavtsev, A.A.; Bezsudnova, Y.I.; Perova, T.S.; Geloen, A.; Lysenko, V.; et al. Cytotoxicity control of silicon nanoparticles by biopolymer coating and ultrasound irradiation for cancer theranostic applications. Nanotechnology 2017, 28. [CrossRef]

61. Icart, L.P.; Santos, E.R.F.; Aguero, L.; Andrade, L.R.; de Souza, C.Z.; d'Avila, L.A.; Zaldivar, D.; Dias, M.L. Paclitaxel-loaded PLA/PEG/fluorescein anticancer agent prepared by Ugi reaction. Int. J. Polym. Mater. Polym. Biomater. 2018, 67, 776-782. [CrossRef]

62. Hosseini, L.; Mahboobnia, K.; Irani, M. Fabrication of PLA/MWCNT/Fe $3 \mathrm{O}_{4}$ composite nanofibers for leukemia cancer cells. Int. J. Polym. Mater. Polym. Biomater. 2016, 65, 176-182. [CrossRef] 
63. Li, X.B.; Li, N.; Kastytis, S.; Li, H.; Zhang, C.; Peng, M.; Zhang, Q.; Hua, K.; Guo, L.; Li, F.; et al. Doxorubicin-loaded dextran-modified goldmag nanoparticles for targeting hepatocellular carcinoma. $J$. Biomed Nanotechnol. 2018, 14, 1135-1146. [CrossRef] [PubMed]

64. Hou, K.-T.; Liu, T.-I.; Chiu, H.-C.; Chiang, W.-H. DOX/ICG-carrying $\gamma$-PGA-g-PLGA- based polymeric nanoassemblies for acid-triggered DOX release combined with NIR-activated photothermal. Eur. Polym. J. 2019, 110, 283-292. [CrossRef]

65. Manivasagan, P.; Bharathiraja, S.; Moorthy, M.S.; Oh, Y.-O.; Seo, H.; Oh, J. Marine biopolymer-based nanomaterials as a novel platform for theranostic applications. Polym. Rev. 2017, 57, 631-667. [CrossRef]

66. Helaly, F.M.; El Nashar, D.E.; Khalaf, A.I.; Abdelhamid, H.F.; Wietrzyk, J.; Psurski, M.; Soliman, A. Slow-release nanopolymeric biodegradable composites holding doxorubicin and evaluation its antiproliferative potency on cancer. Polym. Compos. 2017, 38, E34-E41. [CrossRef]

67. Quinones, J.P.; Jokinen, J.; Keinanen, S.; Covas, C.P.; Bruggemann, O.; Ossipov, D. Self-assembled hyaluronic acid-testosterone nanocarriers for delivery of anticancer drug. Eur. Polym. J. 2018, 99, 384-393. [CrossRef]

68. Brzezinski, M.; Wedepohl, S.; Kost, B.; Calderon, M. Nanoparticles from supramolecular polylactides overcome drug resistance of cancer cells. Eur. Polym. J. 2018, 109, 117-123. [CrossRef]

69. Chevalier, M.T.; Rescignano, N.; Martin-Saldana, S.; Gonzalez-Gomez, A.; Kenny, J.M.; Roman, J.S.; Mijangos, C.; Álvarez, V.A. Non-covalently coated biopolymeric nanoparticles for improved tamoxifen delivery. Eur. Polym. J. 2017, 95, 348-357. [CrossRef]

70. Chen, H.; Ruckenstein, E. Micellar Structures in Nanoparticle-Multiblock Copolymer. Langmuir 2014, 30, 3723-3728. [CrossRef]

71. Wu, C.; Yang, J.; Xu, X.; Gao, C.; Lu, S.; Liu, M. Redox-responsive core-cross-linked mPEGylated starch micelles as nanocarriers for intracellular anticancer drug release. Eur. Polym. J. 2016, 83, 230-243. [CrossRef]

72. Hoang, N.H.; Lim, C.; Sim, T.; Lee, E.S.; Youn, Y.S.; Kim, D.; Oh, K.T. Characterization of a triblock copolymer, poly(ethylene glycol)-polylactide-poly(ethylene glycol), with different structures for anticancer drug delivery applications. Polym. Bull. 2017, 74, 1595-1609. [CrossRef]

73. Guo, Q.; Guan, D.; Dong, B.; Nan, F.; Zhang, Y. Charge-conversional binary drug delivery polymeric micelles for combined chemotherapy of cervical cancer. Int. J. Polym. Mater. Polym. Biomater. 2015, 64, 978-987. [CrossRef]

74. Dai, Y.; Zhang, L.; Xiang, R.; Wan, Y.; Pan, X.; Zheng, L. Polymeric micelles with photo-activated proton release behavior for enhanced tumor extracellular $\mathrm{pH}$ targeting and drug release. Eur. Polym. J. 2017, 96, 69-78. [CrossRef]

75. Zamani, M.; Rostamizadeh, K.; Manjili, H.K.; Danafar, H. In vitro and in vivo biocompatibility study of folate-lysine-PEG-PCL as nanocarrier for targeted breast cancer drug delivery. Eur. Polym. J. 2018, 103, 260-270. [CrossRef]

76. Mishra, P.; Dey, R.K. Developement of docetaxel-loaded PEG-PLA nanoparticles using surfactant-free method for controlled release studies. Int. J. Polym. Mater. Polym. Biomater. 2018, 67, 535-542. [CrossRef]

77. Zhang, L.; Wu, L.; Cao, Y.; Wu, Y.; Chen, J.; Ni, C. Studies on preparation and $\mathrm{pH} /$ redox responsiveness of zwitterionic nanomicelles of poly[lysine-co-N, N-bis(acryloyl) cystamine -co-dodecylamine]. Int. J. Polym. Mater. Polym. Biomater. 2018, 67, 528-534. [CrossRef]

78. Rooj, B.; Mandal, U. Study carbon dots in micellar media. Med. Anal. Chem. Int. J. 2019, 3. [CrossRef]

79. Volsi, A.L.; Fiorica, C.; D'Amico, M.; Scialabba, C.; Palumbo, F.S.; Giammona, G.; Licciardi, M. Hybrid gold/silica/quantum dots supramolecular-nanostructures encapsulated in polymeric micelles as potential theranostic tool for targeted cancer therapy. Eur. Polym. J. 2018, 105, 38-47. [CrossRef]

80. Xue, Y.; Tian, J.; Xu, L.; Liu, Z.; Shen, Y.; Zhang, W. Ultrasensitive redox-responsive porphyrin-based polymeric nanoparticles for enhanced photodynamic therapy. Eur. Polym. J. 2019, 110, 344-354. [CrossRef]

81. He, C.; Yang, Q.; Tan, L.; Liu, B.; Zhu, Z.; Gong, B.; Yu, M.S.; Shao, Z.F. Design and synthesis of redox and oxidative dual responsive block copolymer micelles for intracellular drug delivery. Eur. Polym. J. 2016, 85, 38-52. [CrossRef]

82. Picos-Corales, L.A.; Garcia-Carrasco, M.; Licea-Claverie, A.; Chavez-Santoscoy, R.A.; Serna-Saldivar, S.O. NIPAAm-containing amphiphilic block copolymers with tailored LCST:aggregation behavior, cytotoxicity and evaluation as carriers of indomethacin, tetracycline and doxorubicin. J. Macrom. Sci. Part A 2019. [CrossRef] 
83. Zhang, C.; Wang, Y.; Zhao, Y.; Liu, H.; Zhao, Y.; Li, X.; Lin, Q. Biodegradable micelles for NIR/GSH -triggered chemotherapy of cancer. Nanomaterials 2019, 9, 91. [CrossRef] [PubMed]

84. Alsuraifi, A.; Curtis, A.; Lamprou, D.A.; Hoskins, C. Stimuli responsive polymeric systems for cancer therapy. Pharmaceutics 2018, 10, 136. [CrossRef] [PubMed]

85. Zhang, W.; Song, Y.; Eldi, P.; Guo, X.; Hayball, J.D.; Garg, S.; Albrecht, H. Targeting prostate cancer cells with hybrid elasti-like polypeptide/liposome nanoparticles. Int. J. Nanomed. 2018, 2018, 293-305. [CrossRef] [PubMed]

86. Gomez-Vazquez, D.; Cajero-Zul, L.R.; Torres-Avalos, J.A.; Sandoval-Garcia, K.; Cortes-Ortega, J.A.; Lopez-Dellamary, F.A.; Soltero-Martínez, J.F.A.; Martínez-Richa, A.; Nuno-Donlucas, S.M. Homogeneous hydrogels made with acrylic acid, acrylamide and chemically functionalized carbon nanotubes. J. Macromol. Sci. Part A 2019. [CrossRef]

87. Ahmed, E.M. Hydrogel:preparation, characteriztion, and applications; a review. J. Adv. Res. 2015, 6, $105-121$. [CrossRef] [PubMed]

88. Akhtar, M.F.; Hanif, M.; Ranjha, N.M. Methods of synthesis of hydrogels. A Review. Saudi Pharm. J. 2016, 24, 554-559. [CrossRef]

89. Senapati, S.; Mahanta, A.K.; Kumar, S.; Maiti, P. Controlled drug delivery vehicles for cancer treatment and their performance. Signal Transduct. Targ. Ther. 2018, 3, 7. [CrossRef]

90. Haq, M.A.; Su, Y.; Wang, D. Mechanical properties of PNIPAM based hydrogels:a review. Mat. Sci. Eng. C 2017, 70, 842-855. [CrossRef]

91. Del Valle, L.J.; Diaz, A.; Puiggali, J. Hydrogels for biomedical applications:cellulose, chitosan and protein/peptide derivatives. Gels 2017, 3, 27. [CrossRef]

92. Furuike, T.; Komoto, D.; Hashimoto, H.; Tamura, H. Preparation of chitosan hydrogel and its solubility in organic acids. Int. J. Biolog. Macromol. 2017, 104, 1620-1625. [CrossRef]

93. Abou Taleb, M.F.; Alkahtani, A.; Mohamed, S.K. Radiation synthesis and characterization of sodium alginate/chitosan/hydroxyapatite nanocomposite hydrogels; a drug delivery system for liver cancer. Polym. Bull. 2015, 72, 725-742. [CrossRef]

94. Narayanaswamy, R.; Torchilin, V.P. Hydrogels and their applications in targeted drug delivery. Molecules 2019, 24, 603. [CrossRef] [PubMed]

95. El Nemr, A.; Serag, E.; El-Magharaby, A.; Fathy, S.A.; Abdel Hamid, F.F. Manufacturing of pH sensitive PVA/PVP/MWCNT and PVA/PEG/MWCNT nanocomposites: An approach for significant drug release. J. Macromol. Sci. Part A 2019. [CrossRef]

96. Abdullah, O.; Minhas, M.U.; Ahmad, M.; Ahmad, S.; Ahmad, A. Synthesis of hydrogels for combinatorial delivery of 5-fluorouracil and leucovorin calcium in colon cancer; optimization, in vitro characterization and its toxicological evaluation. Polym. Bull. 2019, 76, 3017-3037. [CrossRef]

97. Rao, Z.-K.; Chen, Z.-M.; Chen, R.; Zhu, H.-Y.; Li, Y.; Liu, Y.; Hao, J.Y. Investigation of a novel thermogelling hydrogel for a versatility of drugs delivery. J. Macrom. Sci. Part A 2019, 56, 26-33. [CrossRef]

98. Kim, H.S.; Yang, J.; Kim, K.; Shin, U.S. Biodegradable and injectable hydrogels as an immunosuppressive drug delivery system. Mat. Sci. Eng. C 2019, 98, 472-481. [CrossRef]

99. Xia, B.; Zhang, W.; Shi, J.; Li, J.; Chen, Z.; Zhang, Q. NIR light-triggered gelling in situ of porous silicon nanoparticles/PEGDA hybrid hydrogels for localized combinatorial therapy of cancer cells. J. Appl. Polym. Sci. 2019, 136. [CrossRef]

100. Birajdar, R.P.; Patil, S.B.; Alange, V.V.; Kulkarni, R.V. Electro-responsive polyacrylamide-grafted-gum ghatti copolymer for transdermal drug delivery application. J. Macromol. Sci. Part A 2019, 56, 306-315. [CrossRef]

101. Chai, Q.; Jiao, Y.; Yu, X. Hydrogels for biomedical applications; their characteristics and mechanisms behind them. Gels. 2017, 3, 6. [CrossRef]

102. Tsintou, M.; Wang, C. Nanobiomaterials, Science, Developement and Evaluation; Woodhead: London, UK, 2017; pp. 87-124.

103. Yuan, S.; Li, X.; Shi, X.; Lu, X. Preparation of multiresponsive nanogels and their controlled release properties. Colloid Polym. Sci. 2019, 297, 613-621. [CrossRef]

104. Garcia, M.C.; Cuggino, J.C. 12. Stimulus responsive nanogels for drug delivery. In Stimuli Responsive Polymeric Nanocarriers for Drug; Makhlouf, A.S.H., Abu-Tahib, N.Y., Eds.; Woodhead Publ: London, UK, 2018; Volume 1, pp. 321-341. 
105. Neamtu, I.; Rusu, A.G.; Diaconu, A.; Nita, I.E.; Chiriac, A.P. Basic concepts and recent advances in nanogels as carrier for medical applications. Drug Deliv. 2017, 24, 539-557. [CrossRef]

106. Yadav, H.K.S.; Al Halabi, N.A.; Alsalloum, G.A. Nanogels as novel drug delivery systems-A review. J. Pharm. Pharm. Res. 2017, 1, 1-8.

107. Chambre, L.; Degirmanci, A.; Sanyal, R.; Sanial, A. Multi-functional nanogels as theranostic platforms: Exploiting reversible and nonreversible linkages for targeting, imaging and drug delivery. Bioconjug. Chem. 2018, 29, 1885-1896. [CrossRef]

108. Pethe, A.M.; Yadav, K.S. Polymers, responsiveness and cancer therapy. Artif. Cells Nanomed. Biotechnol. 2019, 47, 395-405. [CrossRef]

109. Soni, G.; Yadav, K.S. Nanogels as potential nanomedicine carrier for treatment of cancer, a mini review. Saudi Pharm. J. 2016, 24, 133-139. [CrossRef]

110. Luo, Y.-L.; Zhang, X.-Y.; Fu, J.-Y.; Xu, F.; Chen, Y.-S. Novel temperature and pH dual-sensitive PNIP $\mathrm{AM} / \mathrm{CMCS} / \mathrm{MWCNT}$ semi-IPN nanohybrid hydrogels; characterization, and DOX drug release. Int. J. Polym. Mater. Polym. Biomater. 2017, 66, 398-409. [CrossRef]

111. Guo, H.; Li, F.; Qiu, H.; Zheng, Q.; Yang, C.; Tang, C.; Hou, Y. Chitosan-based nanogel enhances chemotherapeutic efficacy of 10-Hydroxycamptothecin against human breast cancer cells. Int. J. Polym. Sci. 2019, 2019, 1914976. [CrossRef]

112. Bardajee, G.R.; Hooshyar, Z. Thermo/pH/magnetic triple sensitive poly (N-isopropylacrylamide-co2dimethylaminoethyl) methacrylate/ sodium alginate modified magnetic graphene oxide nanogel for anticancer drug delivery. Polym. Bull. 2018, 75, 5403-5419. [CrossRef]

113. Fathi, M.; Entezami, A.A.; Arami, S.; Rashidi, M.-R. Preparation of N-isopropylacrylamide/itaconic acid magnetic nanohydrogels by modified starch as a crosslinker for anticancer drug carriers. Int. J. Polym. Mater. Polym. Biomater. 2015, 64, 541-549. [CrossRef]

114. Patra, P.; Seesala, V.S.; Das, D.; Panda, A.B.; Dhara, S.; Pal, S. Biopolymeric nanogel derived from functionalized glycogen towards targeted delivery of 5-fluorouracil. Polymer 2018, 140, 122-130. [CrossRef]

115. Khoee, S.; Yousefalizadeh, G.; Kavand, A. Preparation of dual-targeted redox-responsive nanogels based on pegylated sorbitan for targeted and antitumor drug delivery. Eur. Polym. J. 2017, 95, 448-461. [CrossRef]

116. Khang, E.B.; Lee, G.B.; In, I.; Park, S.Y. pH sensitive fluorescent hyaluronic acid nanogels for tumor-targeting and controlled delivery of doxorubicin and nitric oxide. Eur. Polym. J. 2018, 101, 96-104. [CrossRef]

117. Miceli, E.; Wedepohl, S.; Blanco, E.R.O.; Rimondino, G.N.; Martinelli, M.; Strumia, M.; Molina, M.; Kar, M.; Calderón, M. Semi-interpenetrated denditric, dual-responsive nanogels with cytochrome corona induce controlled apoptosis in HeLa cells. Eur. J. Pharm. Biopharm. 2018, 130, 115-122. [CrossRef]

118. Serrano-Medina, A.; Oroz-Parra, I.; Gomez-Resendiz, V.E.; Licea-Navarro, A.; Licea-Claverie, A.; Cornejo-Bravo, J.M. Temperature and $\mathrm{pH}$ sensitive core-shell nanogels as efficient carriers of doxorubicin with potential application in lung cancer treatment. Int. J. Polym. Mater. Polym. Biomater. 2018, 67, 20-26. [CrossRef]

119. Poma, A.; Pei, Y.; Ruiz-Perez, L.; Rizzello, L.; Battaglia, G. Polymersomes: Synthesis and applications. In Encyclopedia of Polymer Science and Technology; Wiley: Hoboken, NJ, USA, 1964. [CrossRef]

120. Rideau, E.; Dimova, R.; Schwille, P.; Wurm, F.R.; Landfester, K. Liposomes and polymersomes: A comparative review towards cell mimicking. Chem. Soc. Rev. 2018, 47, 8572-8610. [CrossRef]

121. Anajafi, T.; Mallik, S. Polymersome-based drug-delivery strategies for cancer therapeutics. Ther. Deliv. 2015, 6, 521-534. [CrossRef]

122. Mohammadi, M.; Ramezani, M.; Abnous, K.; Alibolandi, M. Biocompatible polymersomes-based cancer theranostics:towards multifunctional nanomedicine. Int. J. Pharm. 2017, 519, 287-303. [CrossRef]

123. de Kruijff, R.M.; Raave, R.; Kip, A.; Molkenboer-Koenen, J.; Roobol, S.J.; Essers, J. Elucidating the influence of tumor presence on the polymersome circulation time in mice. Pharmaceutics 2019, 11, 241. [CrossRef]

124. Aibani, N.; Nesbitt, H.; Marino, N.; Jurek, J.; O’Neill, C.; Martin, C.; Bari, I.D.; Sheng, Y.; Logan, K.; Hawthorne, S.; et al. Electroneutral polymersomes for combined cancer chemotherapy. Acta Biomater. 2018, 80, 327-340. [CrossRef] [PubMed]

125. Zhang, X.-Y.; Zhang, P.-Y. Polymersomes in Nanomedicine-A Review. Curr. Nanosci. 2017, 13, $124-129$. [CrossRef]

126. Manaia, E.B.; Abucafy, M.P.; Chiari-Andreo, B.G.; Silva, B.L.; Oshiro, J.A., Jr.; Chiavacci, L.A. Physicochemical characterization of drug nanocarriers. Int. J. Nanomed. 2017, 12, 4991-5011. [CrossRef] [PubMed] 
127. Alavi, M.; Karimi, N.; Safaei, M. Applications of various types of liposomes in drug delivery systems. Adv. Pharm. Bull. 2017, 7, 3-9. [CrossRef] [PubMed]

128. He, Z.; Liu, K. Combination Strategies for targeted delivery of nanoparticles for cancer therapy. In Applications of Targeted Nano Drugs and Delivery Systems: Nanoscience; Mohapatra, S., Ranjan, S., Eds.; Elsevier: New York, NY, USA, 2018; pp. 191-219.

129. Poy, D.; Shahemabadi, H.E.; Akbarzadeh, A.; Moradi-Sardareh, H.; Ebrahimifar, M. Carboplatin liposomal nanoparticles; preparation,characterization, and cytotoxicity effects on lung cancer in vitro environment. Int. J. Polym. Mater. Polym. Biomater. 2018, 67,367-370. [CrossRef]

130. Foroud, N.; Ardjmand, M.; Heidarinasab, A.; Akbarzadeh, A. Delivery of cisplatin by folic acid -targeted liposomal nanoparticles into liver cancer cell line. Int. J. Polym. Mater. Polym. Biomater. 2018, 67, 865-872. [CrossRef]

131. Yadav, D.; Sandeep, K.; Pandey, D.; Dutta, R.K. Liposomes for drug delivery. J. Biotechnol. Biomater. $2017,7$. [CrossRef]

(C) 2019 by the author. Licensee MDPI, Basel, Switzerland. This article is an open access article distributed under the terms and conditions of the Creative Commons Attribution (CC BY) license (http://creativecommons.org/licenses/by/4.0/). 